\title{
Effects of Fixed and Mixed Delays on Responding under Variable- Interval Schedules
}

James E. Cook

West Virginia University

Follow this and additional works at: https://researchrepository.wvu.edu/etd

\section{Recommended Citation}

Cook, James E., "Effects of Fixed and Mixed Delays on Responding under Variable-Interval Schedules" (2013). Graduate Theses, Dissertations, and Problem Reports. 524.

https://researchrepository.wvu.edu/etd/524

This Thesis is protected by copyright and/or related rights. It has been brought to you by the The Research Repository @ WVU with permission from the rights-holder(s). You are free to use this Thesis in any way that is permitted by the copyright and related rights legislation that applies to your use. For other uses you must obtain permission from the rights-holder(s) directly, unless additional rights are indicated by a Creative Commons license in the record and/ or on the work itself. This Thesis has been accepted for inclusion in WVU Graduate Theses, Dissertations, and Problem Reports collection by an authorized administrator of The Research Repository @ WVU. For more information, please contact researchrepository@mail.wvu.edu. 
Effects of Fixed and Mixed Delays on Responding under Variable-Interval Schedules

\author{
James E. Cook
}

\author{
Thesis submitted \\ to the Eberly College of Arts and Sciences \\ at West Virginia University \\ in partial fulfillment of the requirements for the degree of \\ Master of Science in \\ Psychology
}

Kennon A. Lattal, Ph. D., Chair

Michael Perone, Ph. D.

Steven Kinsey, Ph. D.

Department of Psychology

Morgantown, West Virginia

2013

Keywords: delayed reinforcement; fixed delay; mixed delay; variable-interval schedule; 


\section{ABSTRACT \\ Effects of Fixed and Mixed Delays on Responding under Variable-Interval Schedules}

James E. Cook

Delays to reinforcement are ubiquitous in the natural environment, where those delays often vary. Still, most research examining delayed reinforcement has focused only on fixed delays. Little research has examined the effects of variable delays. Nonresetting fixed and mixed delays to reinforcement were imposed on the responding of 4 pigeons previously maintained on a multiple variable-interval (VI) VI schedule of immediate reinforcement. Mixed delays consisted of two alternating delay values, the mean of which equaled the value of the fixed delay. A progressive delay procedure was used, in which delay durations increased across successive sessions. Conditions included using unsignaled (Mixed-Change) and signaled delays (MixedSignaled) in which both mixed delay values changed across sessions. A third condition (MixedConstant) involved using unsignaled delays in which one of the mixed delay values remained constant while the other progressively increased across sessions. Mixed delay components maintained higher rates of responding in some conditions. Response rates decreased more and changes in interresponse times were greater with unsignaled than signaled delays. With unsignaled delays, changes in responding were a function of the average obtained delay within each component of the multiple schedule, regardless of whether the delays were fixed or mixed. Obtained delays tended to be shorter in the mixed delay component, resulting in higher rates of responding. 


\section{Acknowledgements}

I would like to thank Andy Lattal, Mike Perone, and Steve Kinsey for serving on my committee, for their helpful comments, and for their patience along the way. I would like to thank Ezra Hall for the numerous conversations we had in the lab about this and other projects, both mine and his. I would like to thank Mike Perone for his advice on effectively presenting my research. Lastly, I am especially grateful to Andy Lattal for advising me on this thesis, allowing me to start this project even though we initially disagreed on the expected results (No surprise, he was right.), and encouraging me to pursue this work well beyond what was initially proposed. 
Table of Contents

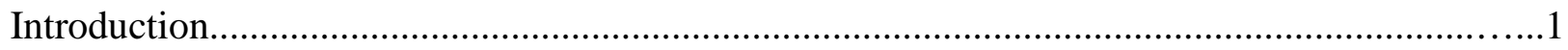

Literature Review............................................................2

Effects of Delay of Reinforcement......................................2

Signaled and Unsignaled Delays.................................6

Distribution and Rate of Reinforcement............................. 9

Fixed and Variable Delays.....................................10

Statement of Problem........................................................ 15

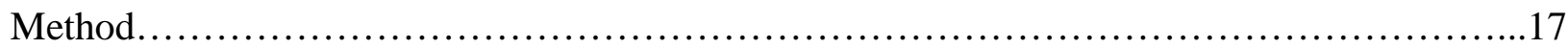

Subjects.....................................................................

Apparatus....................................................................17

Procedure....................................................................18

Pretraining..........................................................18

Progressive-Delay Procedure...........................................18

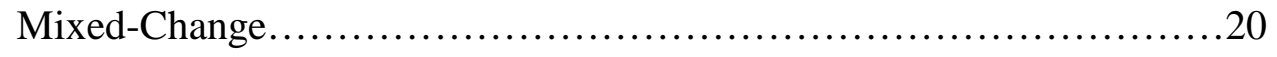

Mixed-Signaled................................................20

Mixed-Constant....................................................20

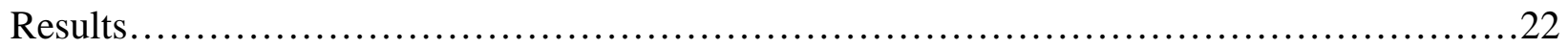

Discussion....................................................................28

Response Rates and Changes in Reinforcement Rates............................28

Response Rates and Delay-Related Variables...................................29

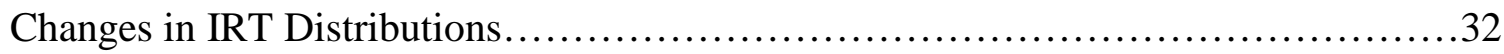

Relation to Previous Experimental Analyses of Delays of Reinforcement................35

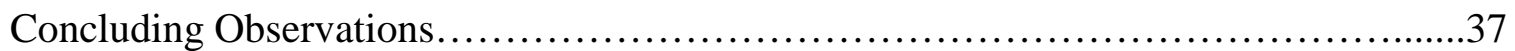

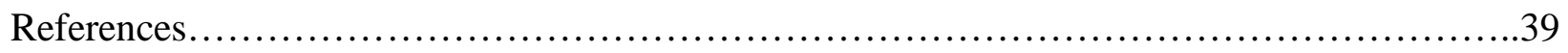


List of Tables

Table 1: Order of Conditions for Each Pigeon.......................................45 


\section{List of Figues}

Figure 1: Absolute response rates in Mixed-Change condition..............................46

Figure 2: Response rates in Mixed-Change condition by programmed and obtained delays.....47

Figure 3: IRT distributions in fixed components of Mixed-Change condition.................48

Figure 4: IRT distributions in mixed components of Mixed-Change condition................49

Figure 5: Absolute response rates in Mixed-Signaled condition............................50

Figure 6: Response rates in Mixed-Signaled condition by programmed and obtained delays...51

Figure 7: IRT distributions in fixed components of Mixed-Signaled condition.................52

Figure 8: IRT distributions in mixed components of Mixed-Signaled condition...............53

Figure 9: Absolute response rates in Mixed-Constant condition...............................54

Figure 10: Response rates in Mixed-Constant condition by programmed and obtained delays...55

Figure 11: IRT distributions in fixed components of Mixed-Constant condition................56

Figure 12: IRT distributions in mixed components of Mixed-Constant condition...............57

Figure 13: Obtained reinforcement rates............................................

Figure 14: Response rates in fixed components of all conditions........................59

Figure 15: Response rates in mixed components of all conditions........................60

Figure 16: Obtained delays as function of programmed delays..........................61

Figure 17: Absolute and proportional response rates in fixed components for all pigeons........62

Figure 18: Absolute and proportional response rates in mixed components for all pigeons......63 


\section{Effects of Fixed and Mixed Delays on Patterns of Responding}

Delays of reinforcement are ubiquitous, occurring whenever time elapses between a response and the delivery of the reinforcer it produces - waiting for someone to answer the phone, listening for the reply to a knock on the door, watching an old computer open a file. Given the regularity with which delays are encountered, it is unsurprising the topic serves as a rich area of study for the experimental analysis of behavior, where it has been demonstrated as one of the principal parameters affecting the efficacy of a reinforcer and the patterns of responding maintained by it (for a review see Lattal, 2010).

Knowledge of the effects of delayed reinforcement is relevant as not all behavior is immediately reinforced. Rarely is the phone call immediately answered. Time creeps in between the last number dialed and the answer on the other end. Furthermore, not all delays are marked merely by time passing. In the moments between response and reinforcer delivery, much can happen. The phone may ring three or eight times, and when on hold, the caller may hear music rather than rings. Numerous distractions may occur in the environment around the caller, and the caller may engage in other behavior while waiting. Such factors make an understanding of the delay itself and its influence on behavior in the natural environment difficult, requiring experiments be conducted to control for other variables.

Many such experiments have examined the effects of delayed reinforcement on behavior, but the full picture is still unrevealed. For instance, compared to the effects of fixed delays to reinforcement, little is known about the effects of variable delays, despite the frequency with which they are encountered. It is unknown if they differentially affect rates and patterns of responding, and if so, to what extent. The following review of the literature examines those 
studies that laid the groundwork for much of the current knowledge regarding delayed reinforcement and forms the basis for a question and experiment designed to assess the effects of fixed and mixed delays to reinforcement on responding previously maintained by immediate reinforcement.

\section{Literature Review}

\section{Effects of Delay of Reinforcement}

The more temporally contiguous two events are, the more likely a cause and effect relation will be attributed to them. This applies not only to observations of events in the physical environment, for instance a fallen tree might be attributed to a recent storm rather than the earlier one that actually felled it, but also to the behavior of organisms (Wallace, 1974). Thus the more temporally contiguous a response (cause) is to the reinforcer produced by it (effect), the stronger the relation between them and the greater the impact that stimulus change will have on future behavior.

Thorndike (1911) in fleshing out those parameters that influenced the law of effect noted one of the key factors that influenced acquiring a response was the interval of time between the response and the satisfaction or discomfort produced by it. The greater the interval of time between the response and its consequence, whether appetitive or aversive, the slower the rate of learning. Following Thorndike, numerous experiments were conducted examining the effect of delay to reinforcement on responses as varied as digging (Watson, 1917), maze-running (Hamilton, 1929), and escaping a problem box (Roberts, 1930) such that by 1933 the evidence on delayed reinforcement supported the following conclusions: Immediate reinforcement was preferred to delayed reinforcement, and delays to reinforcement increased errors and time to 
respond across trials (Renner, 1964). Though research on the effects of delayed reinforcement on discrete trial performance continued (for reviews, see Renner, 1964; Tarpy \& Sawabini, 1974), Skinner (1938) began examining the effects of delayed reinforcement on free-operant responding.

Here too learning was impaired by delays to reinforcement. Skinner (1938) first observed this when he demonstrated that a lever-press response could be acquired following an unsignaled resetting 8-s delay to reinforcement, but the rate of acquisition was slower as the delay increased. Acquisition of responding under unsignaled delayed reinforcement was later investigated by Lattal and Gleeson (1990). Across several experiments, they demonstrated that response acquisition was possible within a few hours under conditions of unsignaled delayed reinforcement with both resetting and nonresetting delays, in which the delay interval between response and reinforcer delivery is or is not reset with each response. The former holds the delay interval static, while the latter may have a nominal or programmed delay and a different obtained delay that consists of the time between the last response and reinforcer delivery. Wilkenfield, Nickel, Blakely, and Poling (1992) later compared the rates of acquisition and patterns of responding of a lever press response for groups of rats in which responding was reinforced never, immediately, or after unsignaled resetting or nonresetting delays of 4-32 s. The response was acquired for all groups except for those that never received reinforcement. Furthermore, speed of acquisition under delayed reinforcement was slower in comparison to immediate reinforcement only for those groups where responding was reinforced after a resetting 16 or 32-s delay.

As further demonstration of the effects of delays on response acquisition, Escobar and Bruner (2007) exposed experimentally naïve rats to a chamber equipped with seven levers. Among these levers, only the center lever produced reinforcers on a tandem random interval (RI) 
$x$ fixed time (FT) $y$ schedule. The values of $x$ and $y$ varied across subjects but always summed to $32 \mathrm{~s}$. The other levers were inoperative but responses on them were recorded. When the FT component was 0 or $2 \mathrm{~s}$, responding was concentrated on the center lever, but as the FT value increased, responding spread across the other levers. These findings illustrate how the temporal contiguity between response and reinforcer focuses responding on that behavior which produces reinforcement (Staddon, 1979). Greater delays allow for the induction and adventitious reinforcement of other behavior (Lattal, 2010), slowing down the acquisition of the response upon which reinforcement is dependent.

To date, the majority of studies that have been conducted on the effects of delays of reinforcement on free-operant responding have focused on their effects on steady-state responding maintained by immediate reinforcement. The results of such studies show that as delays to reinforcement increase, response rates generally decrease from baseline levels. Skinner (1938) began the study of the effects of delays on free-operant responding by imposing unsignaled resetting delays on lever-pressing maintained on fixed-interval (FI) schedules of reinforcement. He observed that the changes in responding when delays were imposed were similar to extinction, but the extent of this similarity was not explored as none of his studies on delayed reinforcement followed the decrease in responding to stability. With each of his subjects that experienced delays, he reintroduced immediate reinforcement and found that responding resumed patterns observed before delays were imposed.

Subsequent researchers expanded on Skinner's work with delayed reinforcement by modifying both the delay and the maintaining reinforcement schedule in various ways. For instance, Ferster (1953) examined the effects of signaled delays to reinforcement. Key-pecking was maintained on a variable-interval (VI) 60-s schedule of reinforcement when he introduced a 
signaled delay in the form of a chamber blackout that began when the schedule requirement was met and terminated with reinforcer delivery. Ferster was able to introduce delays of up to 60 and 120 s gradually with some subjects and abruptly with others with little disruption in responding. Ferster and Hammer (1965) maintained responding using fixed ratio (FR) schedules with signaled delays of up to 24 hours while maintaining the break-run pattern typical of FR schedules. That responding could be maintained with such long delays is attributed to the immediate delivery of the signal that bridged the delay when the schedule requirement was met and the conditioned reinforcing effects that the signal acquired (Dews, 1960; Ferster \& Hammer, 1965; Lattal, 1984; Lattal, 2010).

Dews (1960) compared the effects of resetting and nonresetting unsignaled delays of 10, 30, or 100 s on the key-pecking of pigeons maintained by a schedule of continuous reinforcement (CRF). Cumulative records of the pigeons' responding showed that as the delay increased, rate of responding decreased. Nonresetting delays also maintained higher rates of responding than did comparable resetting delays. The patterns of responding that developed under these delays also were different. Under resetting delays, as each response further postponed the delivery of the reinforcer, responding gradually became more efficient. The subject emitted very few responses followed by a long pause until the delivery of the reinforcer. This pattern persisted for three of the five subjects when transitioned to the nonresetting delay, but for the remaining two, the break-run pattern typical of FR responding developed under delays of 10 and 30 s as nonresetting delays may have had the effect of adventiously reinforcing bursts of responding. Because all subjects transitioned from resetting to nonresetting delays, it is unknown if different patterns of responding might have been obtained when transitioning from nonresetting to resetting delays. 
These early studies laid the groundwork for further studies of delayed reinforcement. In those studies that followed, numerous methods_-signaled and unsignaled delays (Chung 1965; Richards, 1981; Sizemore \& Lattal, 1978), resetting and nonresetting delays (Dews, 1960; Lattal \& Zeigler, 1982), imposing delays on simple (Lattal \& Zeigler, 1982; Richards, 1981; Sizemore \& Lattal, 1977; Sizemore \& Lattal, 1978) and concurrent schedules (Chung, 1965; Chung \& Herrnstein, 1967) — were used, allowing a more complete understanding of the effects of delayed reinforcement.

Signaled and Unsignaled Delays. A common method for assessing the effects of delays involves imposing delays that are either unsignaled, wherein no stimulus change accompanies the delay (Sizemore \& Lattal, 1978), or signaled, wherein some stimulus change occurs at the start of the delay interval and continues to its end. This signal is often a houselight or keylight blackout (Chung, 1965; Chung \& Herrnstein, 1967; Richards, 1981), but other stimuli have been used (Pearce \& Hall 1978; Pierce, Hanford, \& Zimmerman, 1972). In such arrangements, the imposition of a signaled or unsignaled delay functions respectively as either a chain or a tandem schedule. Given that signaled or unsignaled delays constitute different schedules (i.e., chained or tandem, respectively), it is to be expected that these delays have different effects on responding.

These different effects may be observed in the overall response rate and in patterns of responding that develop when these delays are imposed. Richards (1981) compared the effects of imposing signaled or unsignaled delays on responding maintained by immediate reinforcement. Baseline rates of responding were obtained for pigeons responding on VI 60-s or differentialreinforcement-of-low-rate (DRL) 20-s schedules. Signaled and unsignaled delays of .5, 1, 2.5, 5, and $10 \mathrm{~s}$ then were imposed on these schedules across different conditions. The delay gradient obtained using signaled delays depicted a gradual decline in response rates across delay values, 
while delay gradients obtained using unsignaled delays depict increases in response rates at brief ( $\leq 1 \mathrm{~s}$ ) delay values and a much steeper decline as the delay value increases.

These changes examined at the level of response rate may be reflective of changes on a smaller scale, affecting the pattern and structure of responding (Arbuckle \& Lattal, 1988; Dews, 1960; Lattal \& Ziegler, 1982; Richards, 1981; Sizemore \& Lattal, 1978). Lattal and Ziegler (1982) imposed .5-s signaled and unsignaled delays on responding maintained on VI and DRL schedules. When an unsignaled delay was used, they observed a shift in the distribution of interresponse times (IRTs) towards shorter IRTs (<.5 s). Arbuckle and Lattal (1988) replicated and extended these results by showing that brief unsignaled delays also increase the occurrence of bursts of responding (a sequence of responses separated by extremely short IRTs) and that imposing a 5-s delay may shift the distribution of IRTs towards longer intervals. These changes in responding may occur as a result of adventitiously reinforcing bursts of responding in the case of brief delays in which the first response that initiates the delay interval is followed by one or more responses that are temporally contiguous with the delivery of the reinforcer. In the case of longer delays, pausing or behavior other than the target response that occurs during the delay may be adventitiously reinforced. These changes are not observed when the delay is signaled as potential bursts are disrupted by the immediate production of the signal that starts the delay (Lattal \& Ziegler, 1982; Pierce et al., 1972; Richards, 1981). Additionally, the immediate delivery of a signal at the start of the delay interval may have a conditioned reinforcing, eliciting, or overshadowing effect (Lattal, 2010) which may account for the much slower decline in responding when a signaled delay is imposed compared to an unsignaled delay on the same schedule (Richards, 1981). 
Expanding on the work of both Ferster (1953) and Dews (1960), Pierce et al.(1972) in their first experiment, compared different delay procedures on lever-pressing maintained on VI schedules by imposing resetting and nonresetting delays and retracting the lever during the delay. Delay intervals of 10, 30, and 100 s were used. Each delay condition was signaled with a cue light, and for each, similar effects were observed; as the delay interval increased, the response rate decreased and the latency to respond following reinforcer delivery increased. In their second experiment, a comparison of patterns of responding was made between chain VI FI and chain VI FT schedules. Though there were no systematic differences in overall rates of responding or in the VI components, there were differences in the patterns of responding in the FI and FT components. In the FI component, responding was positively accelerated (as is characteristic of responding under FI schedules), while responding was low and flat over time or did not occur during the FT component. That responding in the VI component was maintained at similar rates with both the FI and FT components provides support for the conditioned reinforcing effect of signaled delays.

The potential conditioned reinforcing effect of signaled delays also raises the issue of ensuring that potential variables apart from the delay that may affect responding are controlled. Ferster (1953) found no significant differences in responding on VI 60-s schedules when blackouts of up to 60 or $120 \mathrm{~s}$ were delivered at the beginning of delay intervals and terminated with reinforcement, were made response-dependent but uncorrelated with reinforcers, or were delivered independent of responding. His data, however, consisting only of a few cumulative records, did not give a full picture of responding. Later Pearce and Hall (1978) delivered brief signals either correlated or uncorrelated with reinforcers delivered contingent on lever-pressing. They found that delivery of a signal correlated with reinforcement suppressed response rates 
compared to an uncorrelated signal. When that signal was paired with either immediate or briefly delayed reinforcement, responding was suppressed compared to reinforcement delivered without a signal. These findings led Pearce and Hall to conclude that the stimulus-reinforcer relation formed by the presentation of the signal with the reinforcer overshadowed the responsereinforcer relation between lever-pressing and the reinforcer. The signal also maintained responding when food reinforcement was discontinued, demonstrating the signal had acquired conditioned reinforcing effects. Investigating the function of signals in delayed reinforcement, Lattal (1984) found that delivering a 20-s blackout, whether response-dependent or independent, increased responding maintained on a VI schedule of immediate reinforcement. In his discussion, Lattal suggested that in evaluating the effects of a signaled delay, these effects may be made clearer by comparing the signaled delay condition to a baseline that includes the presentation of the relevant signal presented uncorrelated with the reinforcer.

Distribution and Rate of Reinforcement. Imposing a delay on a schedule of immediate reinforcement affects not only the temporal contiguity between reinforcer deliver and the response that produced it, but also the rate and distribution of reinforcer delivery (Lattal, 1987). This makes it difficult to disentangle the effects of reinforcer delay from a reduction in reinforcement rate when constructing a delay gradient (Richards, 1981). One way of controlling reinforcement rate was described by Chung (1965), who compared the effects of imposing signaled delays of different durations on the distribution of responding in concurrent VI VI schedules. Responding on either of two keys was reinforced on independent VI 1-min schedules during a baseline. In subsequent conditions, the schedules that produced reinforcement on both keys remained the same, but on one key (the delay key) reinforcers occurred after blackoutsignaled delays that varied between 1 and 28 s across different conditions. On the other key, 
responding produced either immediate reinforcement or blackouts of equal length to the delays on the delay key. These blackouts occurred with equivalent frequency as those produced on the delay key but did not terminate with reinforcement, maintaining a constant reinforcement rate between the immediate and delayed reinforcement schedules.

Another way of examining concurrent changes in reinforcement rate when investigating the effects of delayed reinforcement is by comparing responding maintained by a baseline schedule of immediate reinforcement (e.g. a VI 60-s schedule) to a schedule in the delay condition with the same approximate rate and distribution of reinforcement (e. g. a tandem VI 57-s FT 3-s schedule). This was done by Sizemore and Lattal (1978) in comparing the effects of various unsignaled delays on responding previously maintained on a VI 60-s schedule of immediate reinforcement. Shahan and Lattal (2005) also used this method in examining the effects on responding of imposing the same delay value (FT 3 s) on VI schedules of immediate reinforcement of different reinforcement rates (multiple VI 15-s VI 90-s VI 540-s). Using such methods may allow for a clearer evaluation of the effects of delays upon responding when constructing delay gradients.

Fixed and Variable Delays. Almost all studies examining the effects of delayed reinforcement have examined responding when fixed delays are imposed. These delays may be held constant when resetting delays are used (Dews, 1960; Elcoro \& Lattal, 2011; Lattal \& Ziegler, 1982), ensuring that there is always a constant amount of time between the response and the reinforcer with each response during the delay interval resetting the delay. With a nonresetting delay, responses during the delay neither produce reinforcement nor reset the delay (Arbuckle \& Lattal, 1988; Chung, 1965; Chung \& Herrnstein 1967; Elcoro \& Lattal, 2011; Lattal \& Zeigler, 1982; Sizemore \& Lattal, 1978; Shahan \& Lattal, 2005). When these responses do occur during the 
delay interval, this changes the programmed fixed delay to a shorter, often more variable obtained delay. Regardless, if a delay gradient is generated using either the programmed or obtained delays, orderly patterns are produced (Sizemore \& Lattal, 1978). Though there still exists plenty of ground to cover in investigating the effects of fixed delays on responding, a potential area of study has been left open, namely the effects of programmed variable delays to reinforcement on patterns of responding.

Little research has been conducted on the effects of variable delays to reinforcement, but what has been done has suggested more responding occurs on schedules of reinforcement associated with variable delays compared to fixed delays of equivalent average duration. As with other early experiments investigating effects of delays to reinforcement, comparing the effects of reinforcement following fixed and variable delays first examined changes in performance across discrete trials. Logan (1960) compared the running speeds of rats through a runway when traversing the runway produced reinforcement following fixed or mixed delays. Mixed delays consist of two delay intervals that vary from trial to trial. The performance of a group of rats that received reinforcement after a fixed 5-s delay was compared to another group that received reinforcement after mixed delays consisting of a 1-s delay on half of trials and a 9-s delay on the other half of trials, producing an average delay of $5 \mathrm{~s}$ for both groups. Logan found that running speeds were greater for the group that experienced the mixed delays.

Pubols (1962) compared responding in a Y-maze when reinforcement was associated with fixed and mixed delays to reinforcement. One arm of the maze was paired with a fixed delay to reinforcement and the other arm was paired with mixed delays. One of the mixed delay values was always twice the duration of the fixed delay and the other was $0 \mathrm{~s}$, such that the 
average of the mixed delays was equal to the fixed delay. By the end of the experiment all responding for all subjects occurred on the arm associated with the mixed delays.

In a second experiment, Pubols (1962) used a similar procedure to that just described. One arm of a Y-maze was associated with a fixed delay and the other with mixed delays of $0 \mathrm{~s}$ and twice the fixed delay value. Four groups of rats were compared. The mixed delays for two of these groups were 0 and $4 \mathrm{~s}$ and for the other two groups, delays were 0 and $40 \mathrm{~s}$. For one of the groups from each pair, reinforcement was only delivered on those trials where the delay was $0 \mathrm{~s}$ and not following the longer of the two delays. Again, all responding occurred on the arm associated with the mixed delays even when reinforcement was only delivered on half of trials. This demonstrated that in this arrangement additional reinforcers following the longer delay of the pair did not have a substantial impact on responding compared to immediate reinforcement following just half of responses. Given these results, then it would suggest that as the smallest delay value of an array of variable delays approached the value of the fixed delay, less differentiation in responding would be observed. However, this claim was not fully evaluated as all the conditions that Pubols used compared a fixed delay to a pair of delay values, one of which was always twice the value of the fixed delay and the other of which was always $0 \mathrm{~s}$-immediate reinforcement.

These findings are consistent with the results of Herrnstein’s (1964) demonstration that subjects respond more on alternatives associated with aperiodic (VI) schedules of reinforcement than periodic (FI) schedules programmed to deliver an equivalent rate of reinforcement when presented in a concurrent-chains arrangement. In light of these results and those of Logan (1960) and Pubols (1962), Cicerone (1976) compared how pigeons responded between two concurrent independent VI 60-s VI 60-s schedules, one arranging a constant FT delay prior to each 
reinforcer delivery and the other arranging mixed time (MT) delays. Cicerone, like Logan (1960) and Pubols (1962), used two delay values in the MT delay condition, the mean of which was equal to an FT delay of either $8 \mathrm{~s}$ for four pigeons or $30 \mathrm{~s}$ for two other pigeons. He also examined how responding changed as the range of time between the two delay durations comprising the mixed delays varied. Cicerone found that more responding occurred on the schedule associated with the mixed delays, generally, and more responding occurred on the schedule associated with the mixed delay when the range of time between the two delays was greater. The wider the range of the delays in the mixed delay condition, the more responding occurred on the schedule associated with them.

These results were not supported by Richards and Marcattilio (1978). Their experiment was principally designed to assess the effects of stimulus control and behavioral contrast, but in the study, groups of pigeons were exposed to multiple schedules in which one component was paired with immediate reinforcement, and the other component was paired with either fixed or variable delays to reinforcement. Results did not show a significant difference in rates of responding between subjects in the fixed and variable delay conditions. The authors speculated that the reason differences were not observed may have been influenced by a number of factors including the range of interval durations, the mean duration of the delays, and the number of intervals in the variable delay condition.

In part to account for these finding as well as attempt to better estimate the value of reinforcers, or overall effectiveness of reinforcers in maintaining responding, when delivered after equivalent fixed and variable delays, Mazur (1984) developed a quantitative model to describe the different values of reinforcers delivered after fixed and variable delays. Mazur presented two equations, both based on the premise that reinforcers delivered after shorter delays 
have greater value than those delivered after longer delays. The first described the value of a reinforcer when delivered following a fixed delay, and the second equation described the value of a reinforcer when presented following variable delays as a weighted average of the values of the delay intervals. Mazur tested these models by applying them to a series of conditions in which pigeons made a single response to either of two keys. Responding to either of the keys produced a reinforcer following either a standard or adjusting delay. Responses to the standard key delivered reinforcers following FT, MT, variable time (VT), or random time (RT) delays depending on the condition. (The number of intervals that comprise the schedule distinguishes MT delays from VT delays. The former consists of only two intervals and the latter of three or more.) Responses to the adjusting key delivered reinforcers following FT delays that changed depending on the subjects history of responding (i.e., more responses to the standard key decreased the FT delay of the adjusting key and vice versa). Pigeons continued to respond in any one condition until responding was equally distributed between the two keys. The FT delay of the adjusting key when the condition ended was deemed the indifference point, meant to approximate when reinforcers delivered following FT delays were equivalent to those delivered following delays of the relevant schedule in that condition. Mazur's models described the relation between the distribution of delays and the equivalent adjusting FT delay. His model also described how the greater the range of intervals among MT and VT delays, the greater the overall value of reinforcers delivered following those delays, and hence the lower the adjusting equivalent FT delay would be.

Chelonis, King, Logue, and Tobin (1994) in evaluating the effects of variable delays relative to FT delays in a delay discounting procedure compared Mazur's (1984) hyperbolic decay model to two other models: one based on Killeen's (1982) incentive theory and the other 
based on a modification of Baum's (1974) generalized matching law. They compared responding in a nonindependent concurrent VI 30-s VI 30-s schedule arrangement. One of the schedules was associated with a fixed delay that terminated with reinforcement, and the other schedule was associated with either a mixed or a variable delay consisting of intervals that averaged twice the length of the fixed delay and terminated with a reinforcer twice the magnitude of the other schedule. Baum's (1974) model best described the ratio to which subjects allocated responding to the variable delay schedule (i.e. larger-later, self-controlled choice) relative to the fixed delay schedule (i.e. smaller-sooner, impulsive choice). Further, even as the arithmetic mean of the intervals used in the variable-delay schedule remained the same, the ratio of responding that occurred on the variable-delay schedule increased as the range between intervals was increased, and decreased as the standard deviation of the variable delay intervals decreased through the addition of more intervals to the variable delay array.

\section{Statement of Problem}

Delays of reinforcement are encountered all the time, occurring whenever a person sends an e-mail, makes a phone call, or calls for the dog to come. The response rarely, if ever, produces the reinforcer immediately. Delays to reinforcement arise with such regularity that a science of behavior must account for them. As has been described, a greater understanding of delayed reinforcement has been accomplished by controlling for several of the variables that may accompany delays as they occur in the natural environment: changes in rate of reinforcement, delays that are signaled or unsignaled, resetting or nonresetting, fixed or variable. It is this last factor that perhaps has been the least researched and is least understood even though it could be argued that those delays encountered in the natural environment are just as often variable as they are fixed, if not more so: Replies to e-mails sometimes arrive sooner or later, the phone is 
sometimes answered after two or four rings, and the dog may come a few seconds or a minute after it is called.

Most investigations of the effects of delayed reinforcement have used programmed fixed delays. Variable delays have been studied before by either imposing two different delay values in random order, labeled mixed delays (Chelonis et al., 1994; Cicerone, 1976; Logan, 1960; Mazur, 1984; Pubols, 1962), or three or more delay values arranged in random order, labeled variable delays (Bryan, 1978; Chelonis et al., 1994; Mazur, 1984). As noted above, these have been examined before, but mostly in the context of concurrent schedules (e.g., Chelonis et al, 1994; Cicerone, 1976; Mazur, 1984) or in a between-groups design (Richards \& Marcattilio, 1978). Within-subject effects of imposing mixed or variable delays to reinforcement in nonconcurrent schedules previously maintained by immediate reinforcement have not been studied. Given that subjects respond more on schedules associated with variable rather than fixed delays of reinforcement, it may be that mean variable delay values, programmed and obtained, may affect responding in a different manner than equivalent fixed delays. Similar effects that have been observed in responding in concurrent schedules also may be observed in responding on multiple schedules—reinforcement following variable delays may maintain higher rates of responding as the range of intervals is increased. To provide a greater understanding of the effects of variable delays to reinforcement, the purpose of this study was to compare the effects of variable delays to reinforcement on responding previously maintained by immediate reinforcement to those of equivalent fixed delays in a multiple schedule. As the greatest differences in responding between fixed and variable delays was obtained when fewer intervals comprised the variable delay (Chelonis et al., 1994; Mazur, 1984), the effects of FT delays will be compared to MT delays of equivalent average duration. As all of the past research on variable delays has involved signaled 
delays, these were assessed. Unsignaled delays also were examined to assess the potential confounding effects of conditioned reinforcement.

Previous research found the greatest difference in responding between schedules associated with fixed, mixed, and variable delays when there was the widest range between the shortest and longest delays comprising the mixed and variable delays. Larger differences were also observed when the array of delay values comprising the mixed and variable delays included shorter delay values. The effects of mixed delay arrays with different interinterval ranges but equivalent average durations were assessed by comparing two conditions using unsignaled mixed delays. In one condition both mixed delay durations changed, and in the other the shorter delay remained constant while the longer delay increased across sessions.

\section{Method}

\section{Subjects}

Four White Carneau pigeons served as subjects. Water was freely available in the home cage, but food, which consisted of Purina Nutri-Blend ${ }^{\mathrm{TM}}$ pellets, was restricted to maintain pigeons at $80 \%$ of free-feeding weight $\pm 15 \mathrm{~g}$. Pigeons were individually housed and maintained on a 12-hr light/dark cycle in the vivarium.

\section{Apparatus}

A single operant chamber with a work area of $31 \mathrm{~cm} \mathrm{H} \mathrm{x} 30 \mathrm{~cm} \mathrm{~W} \mathrm{x} 33 \mathrm{~cm} \mathrm{~L}$ was used. The work panel was equipped with one 2-cm diameter response key located $14 \mathrm{~cm}$ from the side and $7 \mathrm{~cm}$ below the ceiling. The key was lit by three 7-W 110-V bulbs colored red, white, and blue. One $7 \mathrm{~W}$ 110-V houselight located on the ceiling behind a 2-cm circular aperture located 5 
$\mathrm{cm}$ from the front wall and $12.5 \mathrm{~cm}$ from the side provided illumination during the session. Reinforcers were delivered via a hopper located on the back wall behind a 5-cm circular aperture located $18 \mathrm{~cm}$ below the ceiling and $12.5 \mathrm{~cm}$ from the side. The aperture was illuminated by a 7W, 110-V light during reinforcement, which consisted of 3-s access to pellets in the hopper. Extraneous sounds were be masked by white noise and ventilating fans. The experiment was controlled and data recorded by a PC running Med-PC IV® software located in an adjacent room.

\section{Procedure}

Pretraining. Key-pecking first was reinforced on a multiple CRF CRF schedule before transitioning to a multiple VI VI schedule. Either component of the multiple schedule was associated with a different keylight color. Component VI schedules consisted of intervals randomly selected without replacement from a Catania and Reynolds (1968) distribution with an initial average interval duration of $1 \mathrm{~s}$. Separate lists of intervals were drawn from for each VI component of the multiple schedule. Intervals of these schedules were progressively leaned across sessions to an average duration of $60 \mathrm{~s}$ (VI $60 \mathrm{~s}$ ). Components changed every $10 \mathrm{~min}$. The order of components within each session was determined by selecting randomly without replacement from a list of the two components, ensuring that either component did not occur more than twice in a row. Sessions were conducted 6-7 times per week at approximately the same time each day and terminated after 60 reinforcer deliveries or $300 \mathrm{~s}$ elapsed without a keypeck either component, whichever occurred first.

Progressive-Delay Procedure. This experiment used a progressive-delay procedure described by Jarmolowicz and Lattal (2011) to assess the effects of a greater range of delay durations in a 
more rapid manner than is possible with the typical steady-state arrangement. During the experiment, blocks of baseline, delayed reinforcement, and yoked-immediate reinforcement conditions alternated in a fixed sequence. Sessions were conducted as in pretraining except for the differences noted below.

During baseline sessions reinforcement was delivered on a multiple VI 60-s VI 60-s schedule of immediate reinforcement. Baseline sessions were in effect for a minimum of 13 sessions and continued until responding was stable. Responding was considered stable when the means of responding in both components of the multiple schedule in the first three and last three of the six most recent sessions did not differ from the mean of the six most recent sessions by more than $\pm 10 \%$ with no systematic trends evident as deemed by visual analysis.

In the delayed-reinforcement condition, pigeons responded on a multiple schedule, the components of which were labeled as either the fixed or the mixed component. Fixed components were associated with a red keylight and mixed components were associated with a blue keylight for Pigeons 12 and 60 and vice versa for Pigeon 627 in all conditions and for Pigeon 983 in the Mixed-Change and Mixed-Constant conditions (described below). The keylight color associated with the mixed component for Pigeon 983 was changed to white in the Mixed-Signaled condition (described below) due to especially low response rates in baseline in the presence of the blue keylight. In the fixed component, reinforcement was delivered on a tandem VI 60-s FT $x$-s schedule. In the mixed component, reinforcement was delivered on a mixed (tandem VI 60-s FT y-s) (tandem VI 60-s FT z-s) schedule. The tandem schedule of the mixed component in effect for any particular interval was determined by randomly selecting without replacement from a list of the two tandem schedules, ensuring that either tandem 
schedule did not occur more than twice in a row. The values of $x, y$, and $z$ varied across sessions, but the average of $y$ and $z$ always equaled $x$ for any particular session.

The effects on responding as a function of how the delays were arranged was examined in the conditions outlined below. The order of conditions for each pigeon is shown in Table 1.

Mixed-Change. In this condition the programmed FT delay value in the fixed component $(x)$ was set at $0.5 \mathrm{~s}$ in the first session, $1 \mathrm{~s}$ in the second session, and then increased by $1 \mathrm{~s}$ in each subsequent session to a maximum of $30 \mathrm{~s}$ or until $300 \mathrm{~s}$ elapsed without a keypeck in the interval portion of either the fixed or mixed component. In the mixed component the delay values of $y$ and $z$ were set to $.5 x$ and $1.5 x$, respectively. Delays were unsignaled and nonresetting.

Mixed-Signaled. Sessions in this condition were similar to the Mixed-Change Condition except that delays were signaled with a chamber blackout that lasted the duration of the programmed delay and terminated with reinforcer delivery.

Mixed-Constant. The shorter delay value in the mixed component $(y)$ was held constant at a value of $1 \mathrm{~s}$. The programmed FT delay value of $x$ in the fixed component began at $2 \mathrm{~s}$ in the first session and increased by $1 \mathrm{~s}$ in subsequent sessions to a maximum of $30 \mathrm{~s}$ or until $300 \mathrm{~s}$ elapsed without a keypeck in the interval portion of either the fixed or mixed component. The value of the larger delay in the mixed component (z) was adjusted across successive sessions such that the average of $y$ and $z$ always equaled $x$. Delays were unsignaled and nonresetting.

To control for those changes in responding that occurred as a function of decreases in the reinforcement rate across the delayed-reinforcement condition, a yoked-immediate reinforcement condition was conducted for each condition following termination of the delay condition. This was executed by recording the interreinforcer intervals (IRIs), interblackout intervals (Mixed- 
Signaled condition only), and the order of components from each session of the delayedreinforcement condition. These intervals and order of components were then played back in a multiple schedule of yoked-immediate reinforcement. The yoked-immediate reinforcement control sessions for Mixed-Change and Mixed-Constant conditions were constructed by dividing the IRIs of the delayed-reinforcement condition into their VI interval and FT delay portions and converting these into equivalent tandem yoked time (YT) FI schedules. The yoked-immediate reinforcement control sessions for Mixed-Signaled condition were each constructed by playing back the IRIs of the delayed-reinforcement condition in a yoked interval (YI) schedule. To equate the delivery of signals, the interblackout intervals of each component were played back in a response-independent schedule of blackout delivery with the duration of the blackouts yoked to their respective delayed-reinforcement sessions. These sessions hereafter will be referred to as YI control sessions. Following completion of the YI control sessions, pigeons began baseline sessions for the next condition listed in Table 1.

Data were collected on the frequency, time, and rate of responding in both the interval and delay portions of each component across all conditions. Changes in response rates were assessed only in the interval portion of each component and their equivalent portions of the YI control sessions. This is typical of past research focused on the effects of delays on responding previously maintained by immediate reinforcement (Richards, 1981; Sizemore and Lattal, 1978). Changes in patterns of responding were assessed by examining IRT distributions derived from responding that occurred in both the interval and delay portions of each component. Responding from both portions of the component were included in the IRT analysis because IRTs can be extended over periods of time that include both the interval and delay portions of the component (e.g. the time between the last response in the delay portion that precedes reinforcer delivery and 
the first response of the interval portion that follows). Examining IRT distributions in this way provides a more complete picture of response patterns, including the prevalence of bursts of responding and pausing.

\section{Results}

Figures 1-4 show the results of the Mixed-Change condition. Figure 1 shows the absolute rates of responding across sessions in the interval portions of the fixed and mixed components and their respective YI controls, beginning with the last session of baseline at $0 \mathrm{~s}$. For three of four pigeons, rates of responding tended to decrease rapidly across sessions as the programmed delay was increased before leveling out at a low rate, forming a delay gradient typical of past research (Richards, 1981; Sizemore \& Lattal, 1978). For Pigeon 627, responding declined across the first few sessions before leveling off until the programmed delay reached $15 \mathrm{~s}$ when it declined for several sessions and leveled off again until the end of the condition. For all pigeons responding was generally lower in the delay components than in their controls. A consistent difference in the absolute rate of responding between the fixed and mixed components was only observed with Pigeon 983, where more responding occurred in the mixed component, and even increased above baseline levels at delays of .5 and $1 \mathrm{~s}$.

Figure 2 shows responding calculated as a percentage of the response rate in the last baseline session, determined by dividing the response rate of the interval portion of the relevant session by the response rate in the last baseline session and multiplying by 100 . When viewed as a function of the average programmed delay (left column), there is little difference between these data and the absolute response rates. As delays were nonresetting, there were differences between the programmed delay and the obtained delay, the period of time that elapsed between 
the last response emitted and reinforcer delivery. When viewed as a function of the obtained delay in the right-side graphs of Figure 2, a more typical delay gradient can be observed in the responding of Pigeon 627. Here, the high concentration of data points around obtained delays of less than 2 s occur at levels similar to those data points at the shorter programmed delays in the left panel of Figure 2. Those data points spread across the longer obtained delays occur at levels similar to those data points at longer programmed delays. Also when viewed in this way, the difference between responding in the fixed and mixed components for Pigeon 983 disappears, forming overlapping delay gradients.

Results of the YI components are not displayed in any figures depicting responding as the function of the obtained delay as the obtained delay in all YI components was $0 \mathrm{~s}$.

Past research (Arbuckle \& Lattal, 1988; Elcoro \& Lattal, 2011; Lattal \& Ziegler, 1982) has examined the effect of delayed reinforcement on not only rates of responding, but also changes in IRTs. Figures 3 and 4 show the distribution of IRTs that comprised each pigeon's responding in each component of the delay condition and its respective control. IRTs were recorded and sorted into .25-s bins. The number of IRTs in each bin was divided by the total number of IRTs and multiplied by 100. Generally across sessions of the delay condition from the last session of the baseline condition depicted at $0 \mathrm{~s}$, the distribution of IRTs shifted towards the extremes, with responding being characterized by a large percentage of extremely short $(<.5 \mathrm{~s})$ and extremely long (> 5 s) IRTs with comparatively few IRTs between. Such extreme changes in the distribution of IRTs were not observed across the YI control sessions, which remained largely similar to baseline. This shift is less pronounced for Pigeon 627, but a slight rightward shift in the IRT distribution towards longer IRTs and an increase IRTs $>5$ s can be observed, a change absent in the YI control sessions. 
Figures 5-8 show the results for the Mixed-Signaled condition. Figure 5 shows the absolute rates of responding across sessions in the interval portions of the fixed and mixed signaled delay components and their respective YI controls. Responding decreased gradually across sessions for all pigeons in both delay components at about the same rate. These declines were not as great and were more gradual than those observed in the Mixed-Change condition. Differences in responding between the delay conditions and their yoked controls were not consistently observed across sessions except for Pigeon 12 and during the last few sessions for the other pigeons, when the level of responding decreased in the delay conditions and remained stable in the controls. No systematic differences were observed between the two delay components as the programmed delay increased across sessions when viewed in absolute responses rates or when viewed as a percentage of baseline responses rates as depicted in Figure 6 (left column). Figure 6 (right column) also depicts percentages of baseline response rates as a function of obtained delays, but as obtained delays in the Mixed-Signaled condition deviated little from the programmed delays, there appears to be little difference between the two.

Figures 7 and 8 show the distribution of IRTs in responding during the delay conditions and their YI controls for the fixed and mixed components, respectively. There was little change from baseline in the distribution of IRTs across sessions for the fixed and mixed delay components and only small differences between each delay component and its respective control. In all conditions, there was an increasing trend in the extremely long IRTs across sessions, but as little responding occurred during the blackouts in these sessions, a portion of these long IRTs may be attributed to pausing that occurred during the blackouts. However there was a larger percentage of IRTs in excess of $5 \mathrm{~s}$ and an overall slightly greater rightward shift in the IRTs in 
the delay components, compared to their controls, especially in the later sessions when declines in response rates were greatest.

Figures 9-12 show the results from Mixed-Constant condition. Figure 9 depicts the absolute response rates as a function of the programmed delay. For all pigeons responding was generally lower in the delay condition than in their respective yoked controls, though this difference was only observed in later sessions for Pigeon 627 and was more variable for Pigeon 983. For three of four pigeons, response rates in the fixed delay components decreased rapidly in the early sessions before leveling off at low rate. For Pigeon 627, responding maintained at baseline levels in the fixed delay condition until a 9-s programmed delay was imposed, after which responding decreased rapidly across sessions. In the mixed delay condition, results were more varied. For Pigeon 12, response rates in the mixed delay condition decreased rapidly as programmed delays increased before leveling off at a low rate alongside the fixed delay condition until an average 17-s delay was imposed, after which response rates began to increase across sessions, well above responding in the fixed delay condition. For Pigeon 60, response rates in the mixed delay condition decreased rapidly before leveling off at a low rate, but one slightly higher than the fixed delay condition. For Pigeon 627, responding in the mixed delay condition maintained at about baseline levels until an average 9-s programmed delay was imposed, after which responding rapidly decreased across sessions before leveling off at a low rate while responding continued to decrease in the fixed delay condition. For Pigeon 983, response rates in the mixed delay condition showed a variable but gradually downward trend across sessions as the programmed delay increased which generally remained higher than response rates in the fixed delay condition. 
Figure 10 shows rates of responding in the Mixed-Constant condition as a percentage of the baseline response rate. When plotted as a function of the programmed delay (left column), there is little difference from the absolute response rate data in Figure 9. When plotted as a function of the obtained delay, the data in both fixed and mixed components form typical delay gradients with no systematic difference between the two save that obtained delays were more often shorter in the mixed than in the fixed delay condition.

Figures 11 and 12 show the distribution of IRTs in responding during the delay conditions and their YI controls for the fixed and mixed components, respectively. Generally across sessions of the delay condition, the distribution of IRTs shifted towards the extremes, with responding being characterized by a large percentage of extremely short $(<.5 \mathrm{~s})$ and extremely long ( $>5 \mathrm{~s}$ ) IRTs with comparatively few IRTs between. This shift is not as pronounced for Pigeon 627, especially in the mixed delay component, where there appears to be a more general shift towards longer IRTs, which began when the average 9-s delay was imposed and changes in response rates first were observed. In the YI control components, for all pigeons there was a slight shift in the IRT distributions across sessions towards the longer IRTs, but the distributions otherwise remained largely similar to baseline.

Figure 13 shows the obtained reinforcement rates for each pigeon in all conditions and components. These data indicate that imposing the delays not only reduced the obtained reinforcement rate, but that in some components the changes in responding were such that the obtained rate of reinforcement declined well below the programmed rate of reinforcement. Little to no separation occurred between the obtained reinforcement rate in each delay component and their respective controls. This indicates the YI conditions effectively controlled for changes in 
reinforcement rate, and the differences in responding between delay conditions and their controls are not due to differences in reinforcement rate.

Figures 14 and 15 show responses rates for each pigeon plotted as a percentage of baseline responding across average programmed and obtained delays for each of the conditions in the fixed and mixed components, respectively. Generally, the rates of responding for all three conditions were similar at the short average programmed and obtained delay values $(\sim 0-2 \mathrm{~s}$; top and middle graphs, respectively). Beyond those values, responding maintained at higher rates when delays were signaled. Generally, there were no systematic differences between the rates of responding maintained in the Mixed-Change and Mixed-Constant conditions when viewed as a function of the average programmed and obtained delays, though responding in the MixedConstant condition tended to maintain across longer programmed delays and maintain shorter obtained delays.

Figure 16 displays the temporal contiguity between response and reinforcer delivery by plotting the obtained delay as a function of the programmed delay in the fixed and mixed components across all conditions. For all pigeons, the obtained delays for the Mixed-Signaled condition deviated little from the programmed delay. Obtained delays tended to increase faster and level off at higher obtained delays in the fixed components than in the mixed components. Additionally obtained delays tended to increase faster and level off at higher obtained delays in the Mixed-Change condition than in the Mixed-Constant condition. In comparing Figure 16 to Figures 14 and 15, changes in the obtained delays tended to coincide with changes in response rates, with shorter obtained delays tending to coincide with higher response rates. 
Figures 17 and 18 show the absolute response rates for each pigeon in each condition plotted as a function of obtained delay and those same data plotted as a percentage of baseline responding for the fixed and mixed components, respectively. Pigeons emitted responses at different absolute rates, particularly in sessions associated with low obtained delays, but when viewed as a percentage of baseline responding, there is a greater amount of overlap indicating that similar obtained delays have similar proportional effects on rates of responding.

\section{Discussion}

In this experiment, the effects of imposing programmed, nonresetting fixed and mixed delays on responding previously maintained on a VI schedule of immediate reinforcement were compared. As shown in the results, responding in these conditions changed at the levels of both the session rate of responding and the distribution of IRTs, and the main contributing factors to these changes appeared to be the average obtained delay and whether the delay was signaled or unsignaled. What follows is a discussion of the changes in responding as a function of these variables, as well as how the general results align with those of previous experiments on delay of reinforcement and the possible contributions of procedural differences to any discrepancies in results between this and those previous experiments.

Response rates and changes in reinforcement rates. Imposing delays of reinforcement on responding previously maintained by immediate reinforcement necessarily decreases reinforcement rates, which in turn decreases response rates in conjunction with the effects of the delay. It therefore is necessary to separate the effects of these two confounded changes on responding. The YI control conditions delivered immediate reinforcement at the same rate as corresponding delay conditions. Across all conditions for almost all pigeons, even as 
reinforcement rates decreased, the YI controls maintained response rates at approximately baseline levels while response rates in the delay conditions declined. Thus, although declines in reinforcement rate and the effects of these declines cannot be exorcised from the effects of the delay, the differences between responding in the delay conditions and their YI control counterparts cannot be attributed to changes in reinforcement rate, making them effectively the consequence of the delays. Additionally there were no systematic differences in the reinforcement rates between the fixed and mixed components, so any differences between the fixed and mixed components were the consequence of the way the delays were programmed.

Response rates and delay-related variables. When delays were unsignaled, regardless of whether one or both of the mixed delay intervals changed across sessions, schedules associated with mixed delays maintained higher rates of responding than did those associated with fixed delays for some pigeons, even as average programmed delays were increased. When changes in responding were viewed as a function of the average obtained delay, however, there was little difference between the two components. When viewed in this manner, the results also formed delay gradients typical of the findings of past research (Richards, 1981; Sizemore \& Lattal, 1978) with increases in responding for some pigeons at very brief ( $<.5 \mathrm{~s}$ ) obtained delays, followed by rapid declines in responding before leveling off at a low rate of responding as obtained delays increased. Those differences that did occur between components when delays were unsignaled appeared to have been more a function of the average obtained delay than of whether the delays were fixed or mixed. When the delays were signaled, there were no systematic differences between the two delay components and, typical of past research (Richards, 1981), the rate of decline in responding was more gradual in comparison to that with unsignaled delays. The average obtained delay in Condition B differed little from the average 
programmed delay, so any changes in responding across sessions were more directly the result of changes in the average programmed delay.

Differences in the average obtained delays may account for those differences in responding between fixed and mixed components as the programmed delay was increased, with shorter obtained delays maintaining higher response rates. Across all pigeons in all conditions, systematic differences in responding were only observed when there were systematic differences in the average obtained delay. For example, in the Mixed-Change condition, only Pigeon 983 showed any systematic difference in rates of responding, with higher rates in the mixed component. The data in Figures 2, 14, and 15 show that as average programmed delays increased for Pigeon 983, though both fixed and mixed components maintained average obtained delays shorter than programmed delays, obtained delays were shorter in the mixed delay component. In the Mixed-Change condition there were no systematic differences in the rates of responding between the delay components for the other three pigeons but nor were there systematic differences in the average obtained delays for those pigeons.

In comparing the rates of responding during each condition within and between pigeons, as shown in Figures 14 and 15, the results show similar delay gradients in the Mixed-Change and Mixed-Constant conditions when changes in rates of responding are plotted as a function of average obtained delay for three of four pigeons. The exception was Pigeon 627, where the delay gradients were similar up to an average obtained delay of about $1.5 \mathrm{~s}$. Additionally it can be seen across pigeons that at average obtained delay values of less than $2 \mathrm{~s}$, unsignaled and signaled fixed and mixed delays were functionally equivalent in their effects on response rates. Signaled delays maintained response rates at these levels across longer obtained delays than did 
unsignaled delays. These data support and extend the results of Richards (1981), showing similar effects for some pigeons of both signaled and unsignaled delays when the durations were short.

Considering the difference between programmed and obtained delays, average obtained delays in the Mixed-Signaled condition differed little from the average programmed delays as they increased across sessions. Except for Pigeon 627, average obtained delays generally were shorter in the Mixed-Constant condition than in Mixed-Change condition in sessions with equivalent average programmed delay durations. Subsequently, responding maintained across a greater number of sessions and at higher rates in the Mixed-Constant condition than in MixedChange condition. These results in part support previous research (Chelonis et al., 1994; Cicerone, 1976; Mazur, 1984) showing that variable delay conditions with a wider range in delay interval durations maintained higher rates of responding. Past experiments also examined the effect of manipulating the number of values in the variable delay array, finding less differentiation in responding between variable and fixed delay alternatives as the number of intervals in the variable delay array increased. This would be expected, if adding additional programmed values to a variable delay array reduced the difference in obtained delays between the variable and fixed delay conditions.

In a further comparison of effects between pigeons, as shown in Figures 17 and 18, at the conclusion of baseline, the pigeons had quantitatively different rates of responding, but when unsignaled fixed and mixed delays were imposed, responding changed as a function of the average obtained delay in not only a qualitatively but also a quantitatively similar manner for each pigeon when viewed as a percentage change from baseline rates of responding. These results support and extend the results of Shahan and Lattal (2005) which showed that equivalent delay durations produced equivalent proportional changes in responding across different 
response and reinforcement rates. Given these results it appears that higher rates of responding, by keeping obtained delays shorter, insulates behavior from the potential effects of longer programmed delays. For instance, compare the results of Pigeons 627 and 60. Pigeon 627 responded at a much higher rate than Pigeon 60, as a result the obtained delays for Pigeon 627 are typically shorter, and changes in responding occur much more slowly across sessions. Pigeon 60’s rates of responding were lower, obtained delays typically longer, and changes in responding more rapid. Nevertheless, once an obtained delay of some duration is contacted, it has an equivalent proportional effect on responding, whether that initial rate was low or high.

Similar quantitative changes in responding were not observed in the Mixed-Signaled condition. The likely immediate conditioned reinforcing effect of the signal was sufficient to maintain rates of responding at levels much closer to baseline than did unsignaled delays of equivalent duration. This accounts for the persistence of different rates of responding for each pigeon, and factors in each pigeon's history likely are relevant to why signaled delays of equal duration were differentially effective in maintaining responding for each pigeon.

Changes in IRT distributions. Changes were observed not only in the rates of responding but also in the patterns of responding as reflected in the changes in IRT distributions. In MixedChange and Mixed-Constant conditions, changes in responding in both fixed and mixed delay components were characterized by a shift in the distribution of IRTs towards extremely short (< $.5 \mathrm{~s}$ ) and extremely long (> $5 \mathrm{~s}$ ) IRTs with comparatively fewer moderate duration IRTs which became more extreme across sessions. Though there was a change in the IRT distribution in the Mixed-Signaled condition, this change was more subtle with a gradual shift to longer IRTs and an increase in extremely long IRTs, though not to the degree seen with unsignaled delays. 
The changes in IRT distributions in this experiment were broadly consistent with those found in previous research (Arbuckle \& Lattal, 1988; Elcoro \& Lattal, 2011; Lattal \& Zeigler, 1982). As delays were imposed in the Mixed-Change and Mixed-Constant conditions, the IRT distributions shifted towards extremely short and extremely long IRTs with relatively few in between, taking on a break-run pattern of responding. As in previous research, these changes may be the result of adventitious reinforcement of either bursts of responding, resulting in a shift towards the shorter IRTs, or of pausing, resulting in a shift towards the longer IRTs. These shifts in IRT distributions, whichever way they go, may be a factor of the kind of IRTs that comprise responding in baseline, which may account for why brief delays of reinforcement often, but not always, result in response rate increases.

When signaled delays were imposed, in the Mixed-Signaled condition, there was a slight rightward shift towards longer IRTs across sessions in general and an increase in the percentage of extremely long IRTs specifically. Changes in these extremely long IRTs were gradual and tended to increase as the programmed delays increased, with significant changes only occurring in later sessions when response rates were rapidly decreasing. Given that similar changes in extremely long IRTs occurred in the YI sessions of the Mixed-Signaled condition, these changes were likely the result of the IRTs that occurred between the response that immediately preceded the blackout and the first response that occurred afterwards. As little to no responding occurred during the blackouts, and as blackouts got longer across sessions, these IRTs also became longer. Less dramatic changes in the general distribution of IRTs in the Mixed-Signaled condition may be attributed to the immediate conditioned reinforcing properties of a signal that reliably preceded reinforcement, which may account for the similarity between IRT distributions of the delay condition to those in the YI controls. Additionally as a blackout was used to signal the 
delay this likely truncated potential bursts of responding, preventing their adventitious reinforcement (cf. Lattal \& Ziegler, 1982).

These results illustrate the value of assessing changes in IRT distributions in conjunction with changes in rates of responding. In this experiment, differences in rate of responding were not present between delay sessions and their control in every instance, but in those instances, there often were differences in IRT distributions. This can be seen in Figures 2 and 4 for Pigeon 12 between the session when a programmed average 14-s mixed delay was imposed and its YI control. Response rates in those sessions were similar but the distribution of IRTs was not. Examination of individual cumulative records for these sessions in conjunction with the response rates would result in similar conclusions, but examining changes in IRT distributions as presented in Figures 3, 4, etc. allows the experimenter a more precise analysis of changes in responding at the level of individual sessions as well as those that occur over the breadth of an entire condition.

Examining changes in IRT distributions may also reveal changes in responding that occur over time that are not evident when only changes in response rates are examined. For instance, across the last few sessions for Pigeon 12, overall reinforcement rate and average obtained delays in both delay components remained relatively stable, and changes in not only response rate, but also in IRT distributions occurred. The IRT durations principally remained either extremely short or extremely long, but the percentage of extremely short IRTs increased while the percentage of extremely long IRTs decreased over the last few sessions. This resulted in response rates that were quantitatively similar to those at shorter programmed and equivalent obtained delay values but were qualitatively different when the IRT distributions were examined. Given the equivalent average obtained delays in these sessions, it is possible that these changes 
in IRT distributions were a result of time spent in a condition of delayed-reinforcement. A comparison of results obtained in the progressive-delay procedure to those obtained from steadystate research would be most useful in clarifying these effects.

Relation to previous experimental analyses of delays of reinforcement. The present delay gradients based on the average obtained delays for both fixed and mixed components are consistent with previous research that has examined changes in responding as a consequence of imposing fixed delays (Richards, 1981; Sizemore \& Lattal, 1978). However, this similarity in results between fixed and mixed components is not consistent with previous research that found differences in responding in schedules associated with fixed and mixed delays, with mixed delays maintaining higher rates of responding (Chelonis et al, 1994; Cicerone, 1976; Logan, 1960; Mazur, 1984; Pubols, 1962). Procedural differences between the current and past studies may in part account for these differences. Although some used discrete trial arrangements (Logan, 1960; Mazur, 1984; Pubols, 1962), all of these studies used only signaled delays and some variant of a concurrent schedule, and continued conditions out to stability rather than change delays with each session, any of these differences may have contributed to the difference in results.

All previous studies used only signaled delays, and for those that used pigeons as subjects (Chelonis et al, 1994; Cicerone, 1976; Mazur, 1984; Richards \& Marcattilio, 1978), the signal consisted of darkening the keylights and turning on different houselights associated with either fixed or variable delays. The degree to which using different signals for different delays just as Cicerone (1976), Mazur (1984), and Chelonis et al (1994) did may have facilitated differentiation compared to using the same signal (blackout) in all delay conditions is another question. The chamber blackout used in this study kept obtained delays largely comparable to the 
programmed delays, and though obtained delays were not assessed in previous studies examining variable delays, it seems likely that the signaled delays used in those studies did the same (Pierce et al., 1972). This was not often the case in unsignaled delay conditions, where the obtained delay frequently differed from the programmed delay, thus it is unclear if using resetting delays (signaled or unsignaled) may have produced different results.

All previous studies also used concurrent schedules to compare the effects of fixed and variable delays, excepting Richards and Marcattilio (1978). The extent to which imposing programmed fixed or variable delays on different schedules of reinforcement, including CRF (Mazur ,1984) and VI schedules (Cicerone, 1976), in concurrent schedules or in a single, simple schedule, rather than a multiple schedule, thus avoiding the potential confounding effects of schedule interactions, including but not limited to behavioral contrast and induction (Hemmes \& Eckerman, 1972; Lattal \& Smith, 2011; Reynolds, 1961, 1963; Richards, 1972; Richards \& Marcattilio, 1978; Spealman, 1978; Spealman \& Gollub, 1978), may produce different results also is unclear.

Perhaps the greatest procedural difference between this study and past research was in the use of the progressive-delay procedure. In all previous research, sessions at each delay value continued until responding met some predetermined stability criterion, as is typical of steadystate research. Delay gradients produced by imposing fixed delays on responding previously maintained by immediate reinforcement in steady-state research are well-documented (Richards, 1981; Sizemore \& Lattal, 1978). These gradients typically consist of only a few data points based on the average of the last several sessions of each delay condition and are the fruit of what ultimately may be hundreds of sessions. Reilly and Lattal (2004) used a progressive delay procedure that increased the programmed delay in VI and FI schedules previously maintained by 
immediate reinforcement by $2 \mathrm{~s}$ after each reinforcer delivery. Their results produced more complete delay gradients within one session and these gradients were qualitatively similar to those produced by steady-state procedures across a wider range of delay values than are typically studied. Jarmolowicz and Lattal (2011), upon which the procedures in this study are based, increased the programmed delays imposed on FR schedules across sessions and produced delay gradients qualitatively similar to those in past experiments, just as did this study, in a fraction of the time required to continue each condition to stability. What was potentially sacrificed though was a more in-depth analysis of responding at any one particular delay value and any associated changes in responding that may take time to develop. These results lend support to using a method of more rapidly assessing the effects of different reinforcement parameters when the general parametric function is already well established by the thorough, in-depth analysis of steady-state arrangements. Studying the effects of some variable across a range of different reinforcement parameters within or across sessions may be useful in analyzing drug effects when tolerance, chronic dosing effects, or the time-course of the drug are factors or in the applied realm when circumstances may demand more rapid assessments. Ultimately, though, the results of such a rapid assessment demand their utility be validated by comparison to the results of steady-state conditions.

Concluding Observations. Research into the effects of delayed reinforcement has been conducted since the beginnings of operant psychology (Skinner, 1938). The delays used in these past experiments have been varied in a multitude of manners—signaled, unsignaled, resetting, nonresetting, in concurrent and in simple schedules, in the acquisition and maintenance of responding, and yes, even whether those delays were fixed or variable—but no previous study has directly compared the effects of fixed and variable delays on responding. Most previous 
research focused on the effects of delayed reinforcement have examined the effects of fixed delays to reinforcement, and comparatively little has examined the effects of variable delays, including but not limited to mixed delays, despite the more variable delays that occur in the natural environment. Previous research that has examined the effects of variable delays demonstrated that more responding occurs on alternatives associated with variable delays to reinforcement than with fixed delays of equivalent average duration, suggesting that behavior may be maintained at higher rates on schedules associated with variable delays. The results of this experiment suggest that whether the programmed delays are fixed or variable may not be the relevant factor in the maintenance of responding, but rather the average obtained delays are more directly responsible for the changes observed in responding, though these obtained delays were derived, in part, from the manner in which the delays were programmed. Shorter obtained delays occurred in the mixed delay components than in the fixed delay components and higher rates of responding occurred in the mixed delay components, but when responding was compared between fixed and mixed components at similar obtained delays, there was little difference.

It is not surprising that the present results do not align in every way with those from previous experiments. There are several nontrivial procedural differences between this and past experiments, any of which may have contributed to those discrepancies. Each is grounds for further investigation; however, despite these differences, this experiment produced delay of reinforcement results strikingly similar to those obtained using more conventional methods and extended the analysis of delayed reinforcement effects to situations involving mixed delays. 


\section{References}

Arbuckle, J. L., \& Lattal, K. A. (1988). Changes in functional response units with briefly delayed reinforcement. Journal of the Experimental Analysis of Behavior, 49, 249-263.

Baum, W. M. (1974). On two types of deviation from the matching law: Bias and undermatching. Journal of the Experimental Analysis of Behavior, 22, 231-242.

Bryan, A. J. (1978). Stimulus and schedule effects in delay of reinforcement. (Unpublished doctoral dissertation). West Virginia University, Morgantown, WV.

Catania, A. C., \& Reynolds, G. S. (1968). A quantitative analysis of the responding maintained by interval schedules of reinforcement. Journal of the Experimental Analysis of Behavior, 11, 327-383.

Chelonis, J. J., King, G., Logue, A. W., \& Tobin, H. (1994). The effect of variable delays on self-control. Journal of the Experimental Analysis of Behavior, 62, 33-43.

Chung, S. H. (1965). Effects of delayed reinforcement in a concurrent situation. Journal of the Experimental Analysis of Behavior, 8, 439-444.

Chung, S. H., \& Herrnstein, R. J. (1967). Choice and delay of reinforcement. Journal of the Experimental Analysis of Behavior, 10, 67-74.

Cicerone, R. A. (1976). Preference for mixed versus constant delay of reinforcement. Journal of the Experimental Analysis of Behavior, 25, 257-261.

Dews, P. B. (1960). Free-operant behavior under conditions of delayed reinforcement: I. CRFtype schedules. Journal of the Experimental Analysis of Behavior, 3, 221-234. 
Elcoro, M., \& Lattal, K. A. (2011). Effects of unsignaled delays of reinforcement on fixedinterval schedule performance. Behavioural Processes, 88, 47-52.

Escobar, R., \& Bruner, C. A. (2007). Response induction during the acquisition and maintenance of lever pressing with delayed reinforcement. Journal of the Experimental Analysis of Behavior, 88, 29-49.

Ferster, C. B. (1953). Sustained behavior under delayed reinforcement. Journal of Experimental Psychology, 45, 218-224.

Ferster, C. B., \& Hammer, C. (1965). Variables determining the effects of delay in reinforcement. Journal of the Experimental Analysis of Behavior, 8, 243-254.

Hamilton, E. L. (1929). The effects of delayed incentive on the hunger drive in the white rat. Genetic Psychological Monographs, 5, 131-209.

Hemmes, N. S., \& Eckerman, D. A. (1972). Positive interaction (induction) in multiple variableinterval, differential-reinforcement-or-high-rate schedules. Journal of the Experimental Analysis of Behavior, 17, 51-57.

Herrnstein, R. J. (1964). Aperiodicity as a factor in choice. Journal of the Experimental Analysis of Behavior, 7, 179-182.

Jarmolowicz, D. P. (2011). Rapid assessment of delay-of-reinforcement effects on key-pecking maintained by fixed-ratio schedules. (Unpublished doctoral dissertation). West Virginia University, Morgantown, WV.

Keller, J. V. (1970). Behavioral contrast under multiple delays of reinforcement. Psychonomic Science, 20, 257-258. 
Killeen, P. R. (1982). Incentive theory II. Models for choice. Journal of the Experimental Analysis of Behavior, 38, 217-232.

Lattal, K. A. (1984). Signal functions in delayed reinforcement. Journal of the Experimental Analysis of Behavior, 42, 239-253.

Lattal, K. A. (1987). Considerations in the experimental analysis of reinforcement delay. In Commons, M. L., Mazur, J. E., Nevin, J. A., \& Rachlin, H. (Eds.) Quantitative analyses of behavior (pp. 107-123). Hillsdale, NJ: Lawrence Erlbaum Associates, Publishers.

Lattal, K. A. (2010). Delayed reinforcement of operant behavior. Journal of the Experimental Analysis of Behavior, 93, 129-139.

Lattal, K. A. \& Gleeson, S. (1990). Response acquisition with delayed reinforcement. Journal of the Experimental Psychology: Animal Behavior Processes, 16, 27-39.

Lattal, K. A., \& Smith, J. (2011). Behavioral contrast when responses are maintained by unsignaled delayed reinforcement. Mexican Journal of Behavior Analysis, 37 (3), 7-18.

Lattal, K. A. \& Ziegler, D. R. (1982). Briefly delayed reinforcement: An interresponse time analysis. Journal of the Experimental Analysis of Behavior, 37, 407-416.

Logan, F. A. (1960). Incentive: How the conditions of reinforcement affect the performance of rats. New Haven: Yale University Press.

Mazur, J. E. (1984). Tests of an equivalence rule for fixed and variable reinforcer delays. Journal of Experimental Psychology: Animal Behavior Processes, 10, 426-436. 
Pearce, J. M., \& Hall, G. (1978). Overshadowing the instrumental conditioning of a lever-press response by a more valid predictor of the reinforcer. Journal of Experimental Psychology: Animal Behavior Processes, 4, 356-367.

Pierce, C. H., Hanford, P. V., Zimmerman, J. (1972). Effects of different delay of reinforcement procedures on variable-interval responding. Journal of the Experimental Analysis of Behavior, 18, 141-146.

Pubols, B. H. Jr. (1962). Constant versus variable delay of reinforcement. Journal of Comparative and Physiological Psychology, 55, 52-56.

Reilly, M. P., \& Lattal, K. A. (2004). Within-session delay-of-reinforcement gradients. Journal of the Experimental Analysis of Behavior, 82, 21-35.

Renner, K. E. (1964). Delay of reinforcement: A historical review. Psychological Bulletin, 61, 341-361.

Reynolds, G. S. (1961). An analysis of interactions in a multiple schedule. Journal of the Experimental Analysis of Behavior, 4(2), 107-117.

Reynolds, G. S. (1963). Some limitations on behavioral contrast and induction during successive discrimination. Journal of the Experimental Analysis of Behavior, 6(1), 131-139.

Richards, R. W. (1972). Reinforcement delay: Some effects on behavioral contrast. Journal of the Experimental Analysis of Behavior, 17, 381-394.

Richards, R. W. (1981). A comparison of signaled and unsignaled delay of reinforcement. Journal of the Experimental Analysis of Behavior, 35, 145-152. 
Richards, R. W., \& Marcattilio, A. J. (1978). Stimulus control and delayed reinforcement. Learning and Motivation, 9, 54-68.

Roberts, W. H. (1930). The effect of delayed feeding on white rats in a problem cage. Journal of Genetic Psychology, 37, 35-58.

Shahan, T. A., \& Lattal, K. A. (2005). Unsignaled delay of reinforcement, relative time, and resistance to change. Journal of the Experimental Analysis of Behavior, 83, 201-219.

Sizemore, O. J., \& Lattal, K. A. (1977). Dependency, temporal contiguity, and responseindependent reinforcement. Journal of the Experimental Analysis of Behavior, 27, 119125.

Sizemore, O. J., \& Lattal, K. A. (1978). Unsignaled delay of reinforcement in variable-interval schedules. Journal of the Experimental Analysis of Behavior, 30, 169-175.

Skinner, B. F. (1938). The behavior of organisms: An experimental analysis. Acton, MA: Copley Publishing Group.

Spealman, R. D. (1978). Interactions in multiple schedules: Negative induction with squirrel monkeys. Journal of the Experimental Analysis of Behavior, 30, 315-327.

Spealman, R. D., \& Gollub, L. R. (1974). Behavioral interactions in multiple variable-interval schedules. Journal of the Experimental Analysis of Behavior, 22, 471-481.

Staddon, J. E. R. (1979). Operant behavior as adaptation to constraint. Journal of Experimental Psychology: General, 108, 48-67. 
Tarpy, R. M., \& Sawabini, F. L. (1974). Reinforcement delay: A selective review of the past decade. Psychological Bulletin, 81, 984-987.

Thorndike, E. L. (1911). Animal Intelligence. New York: MacMillan.

Wallace, W. A. (1974). Aquinas on the temporal relation between cause and effect. The Review of Metaphysics, 27 (3), 569-584.

Watson, J. B. (1917). The effect of delayed feeding upon reaction. Psychobiology, 1, 51-60.

Wilkenfield, J., Nickel, M., Blakely, E, \& Poling, A. (1993). Acquisition of lever-press responding in rats with delayed reinforcement: A comparison of three procedures. Journal of the Experimental Analysis of Behavior, 58, 431-443. 
Table 1

Order of Conditions for Each Pigeon

Pigeon Order of Conditions

12 Mixed-Change, Mixed-Signaled, Mixed-Constant

60 Mixed-Constant, Mixed-Change, Mixed-Signaled

627 Mixed-Constant, Mixed-Signaled, Mixed-Change

983 Mixed-Change, Mixed-Constant, Mixed-Signaled 


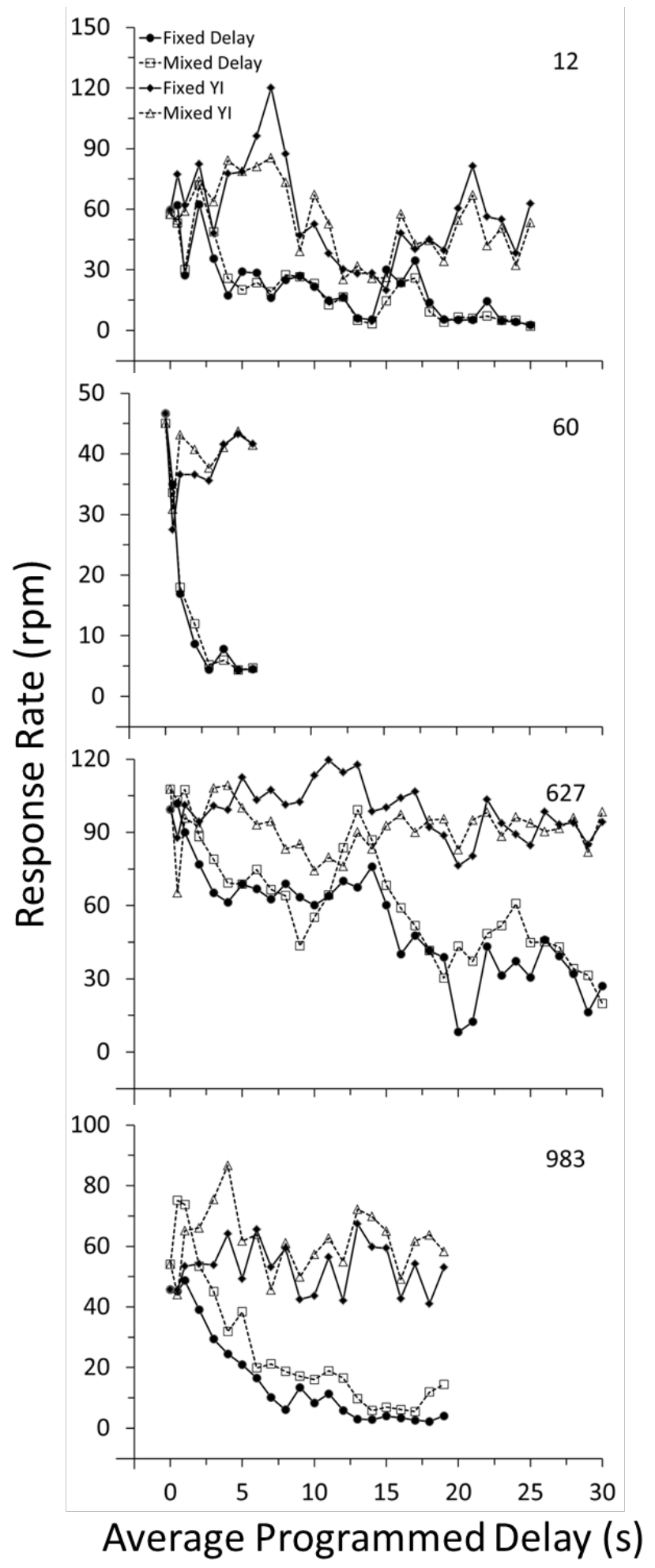

Figure 1. Absolute response rates in the Mixed-Change condition measured as responses per minute (rpm). The last session of baseline is listed at $0 \mathrm{~s}$. 


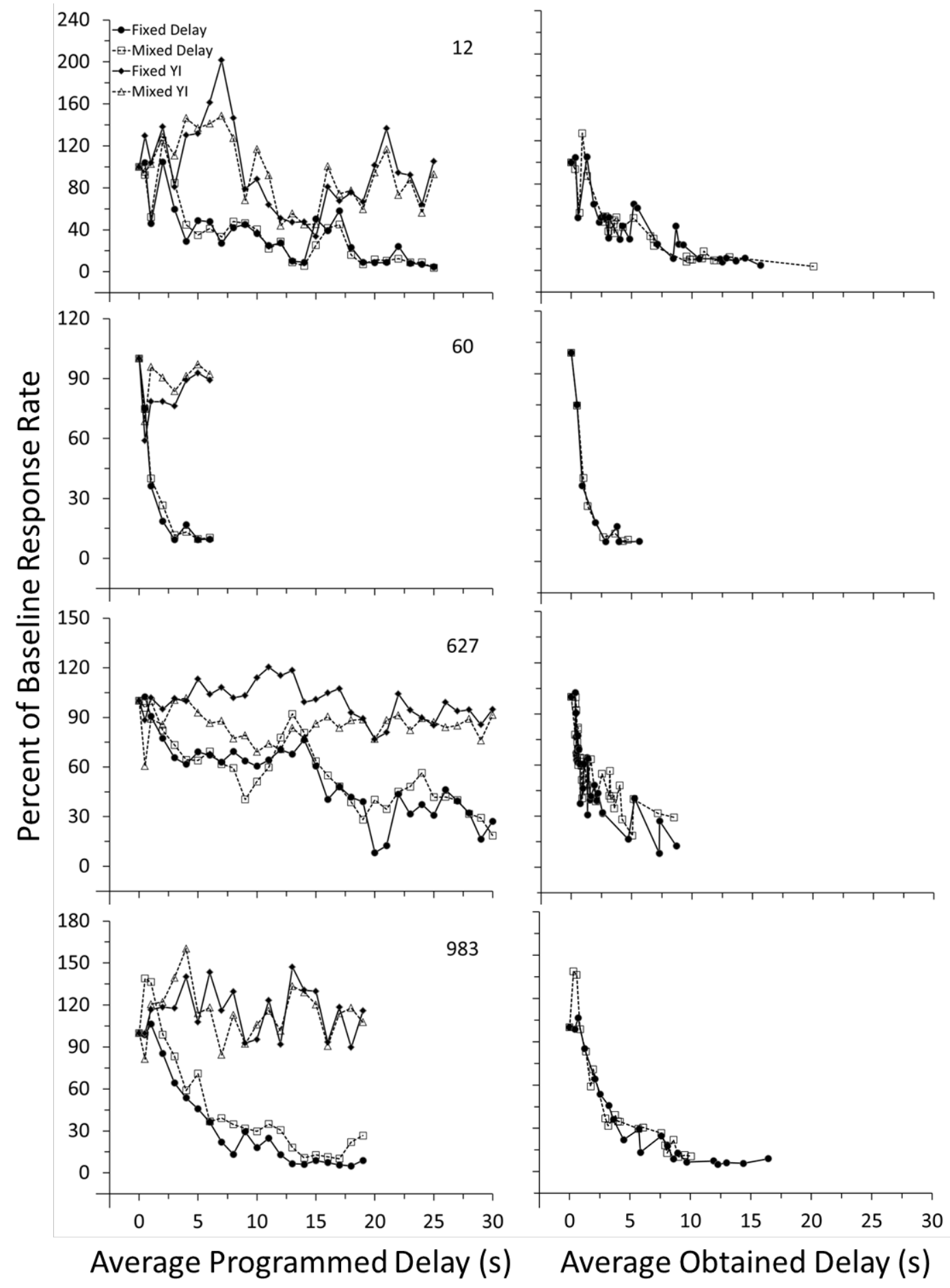

Figure 2. Response rates in the Mixed-Change condition, measured as a percentage of responding in the last baseline session as a function of the average programmed (left) and obtained delay (right). 


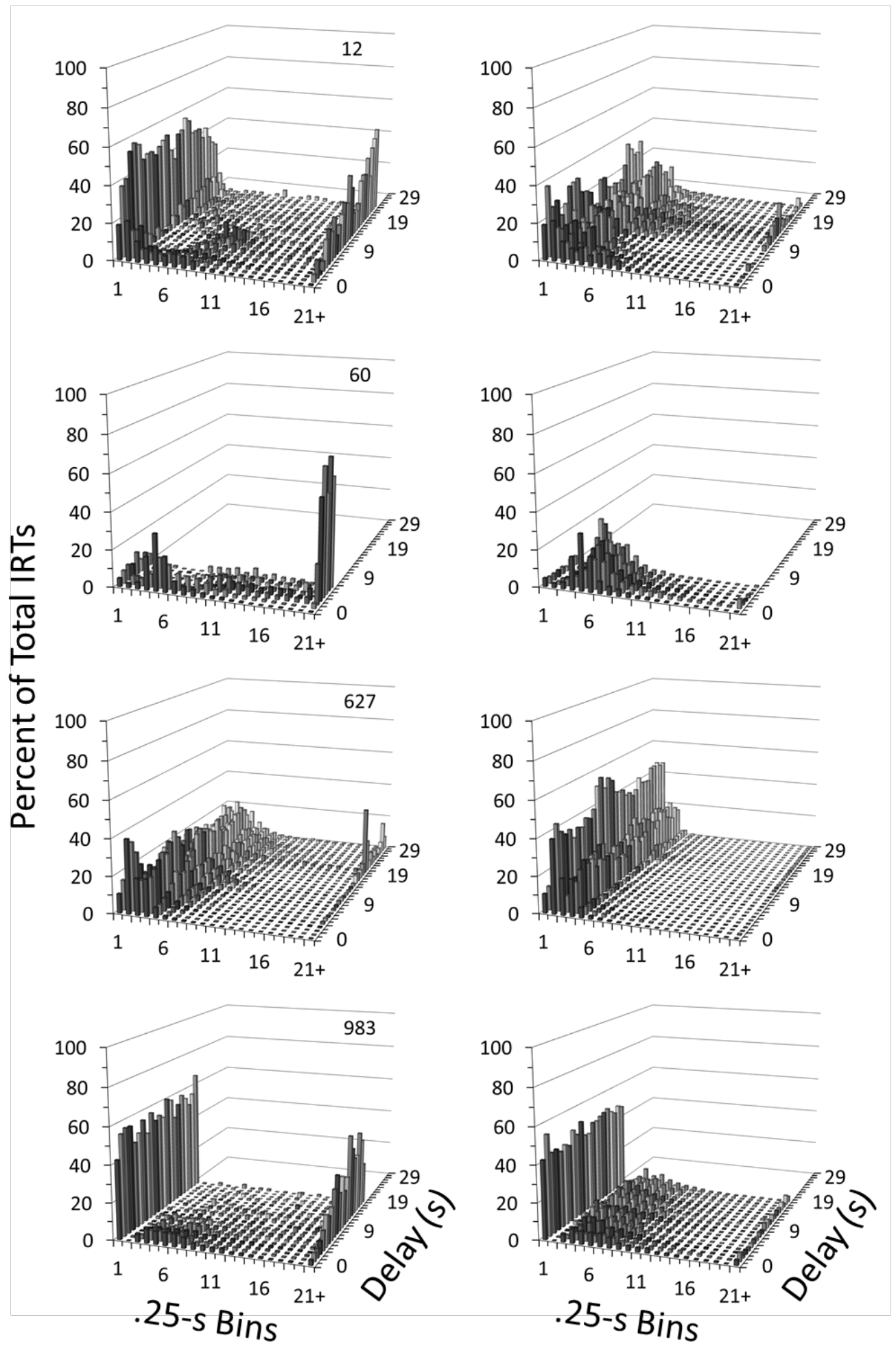

Figure 3. IRT distributions in the fixed delay component (left) and its YI control (right) of the Mixed-Change condition arranged as a function of the average programmed delay. 


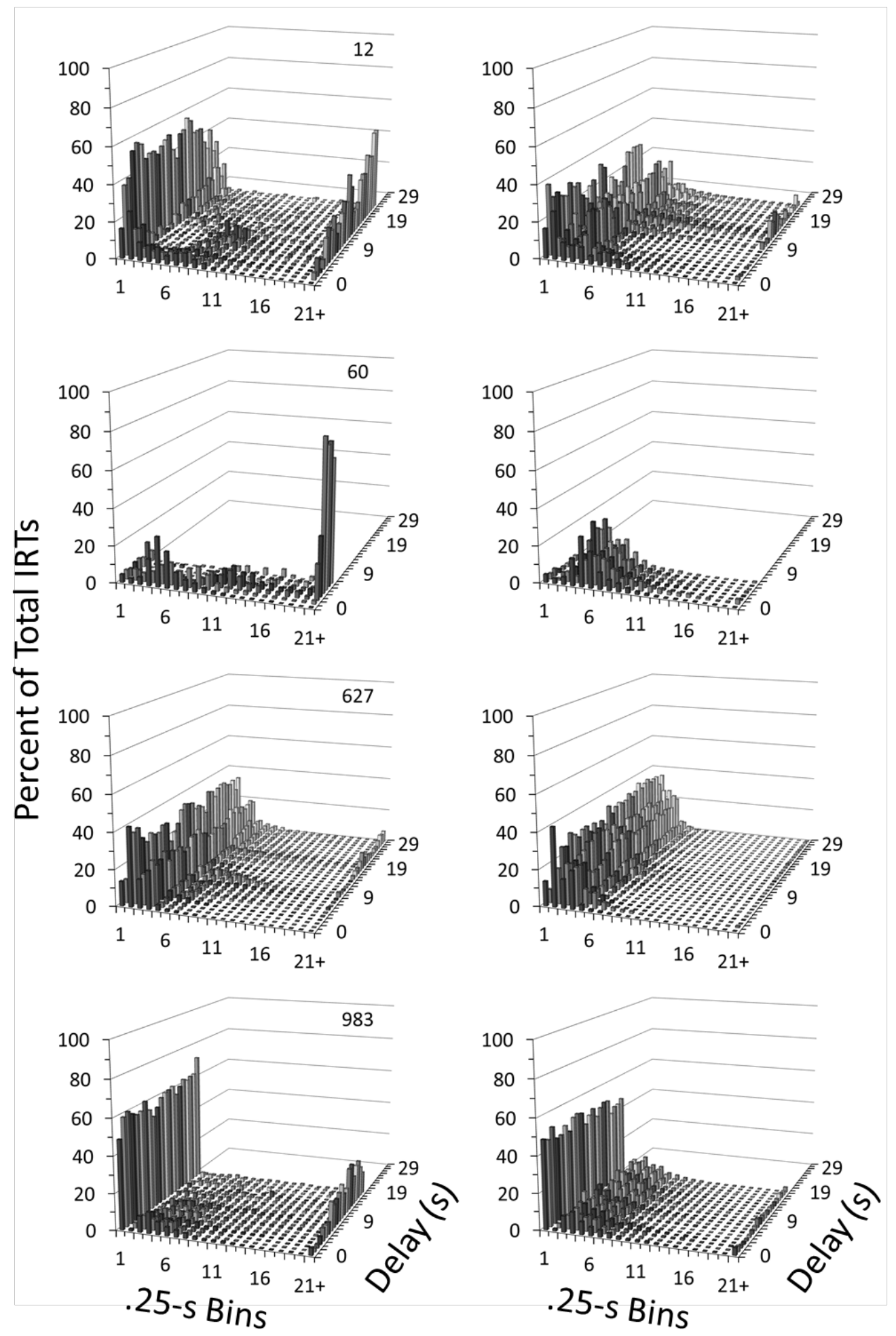

Figure 4. IRT distributions in the mixed delay component (left) and its YI control (right) of the Mixed-Change condition arranged as a function of the average programmed delay. 


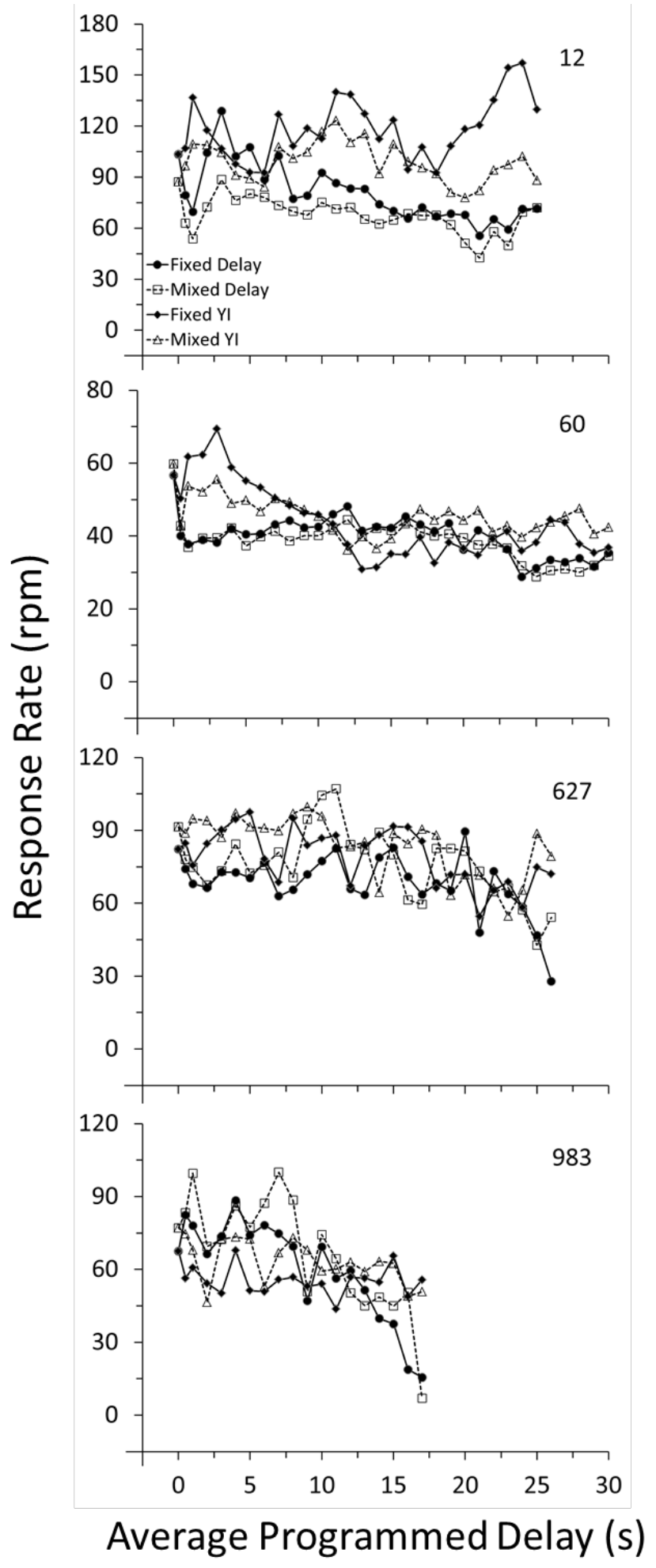

Figure 5. Absolute response rates in the Mixed-Signaled condition measured as responses per minute (rpm). The last session of baseline is listed at $0 \mathrm{~s}$. 


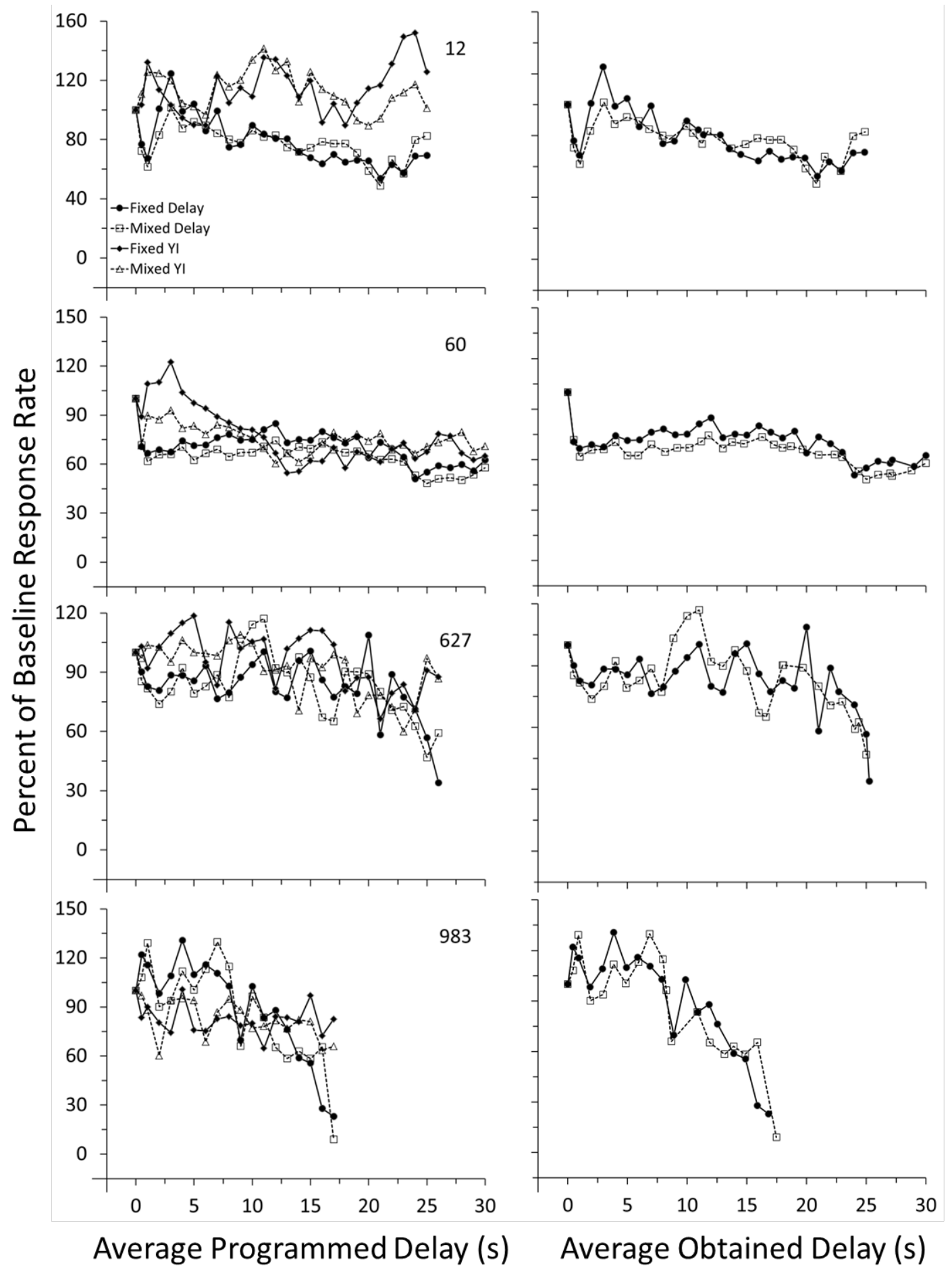

Figure 6. Response rates in the Mixed-Signaled condition, measured as a percentage of responding in the last baseline session as a function of the average programmed (left) and obtained delay (right). 

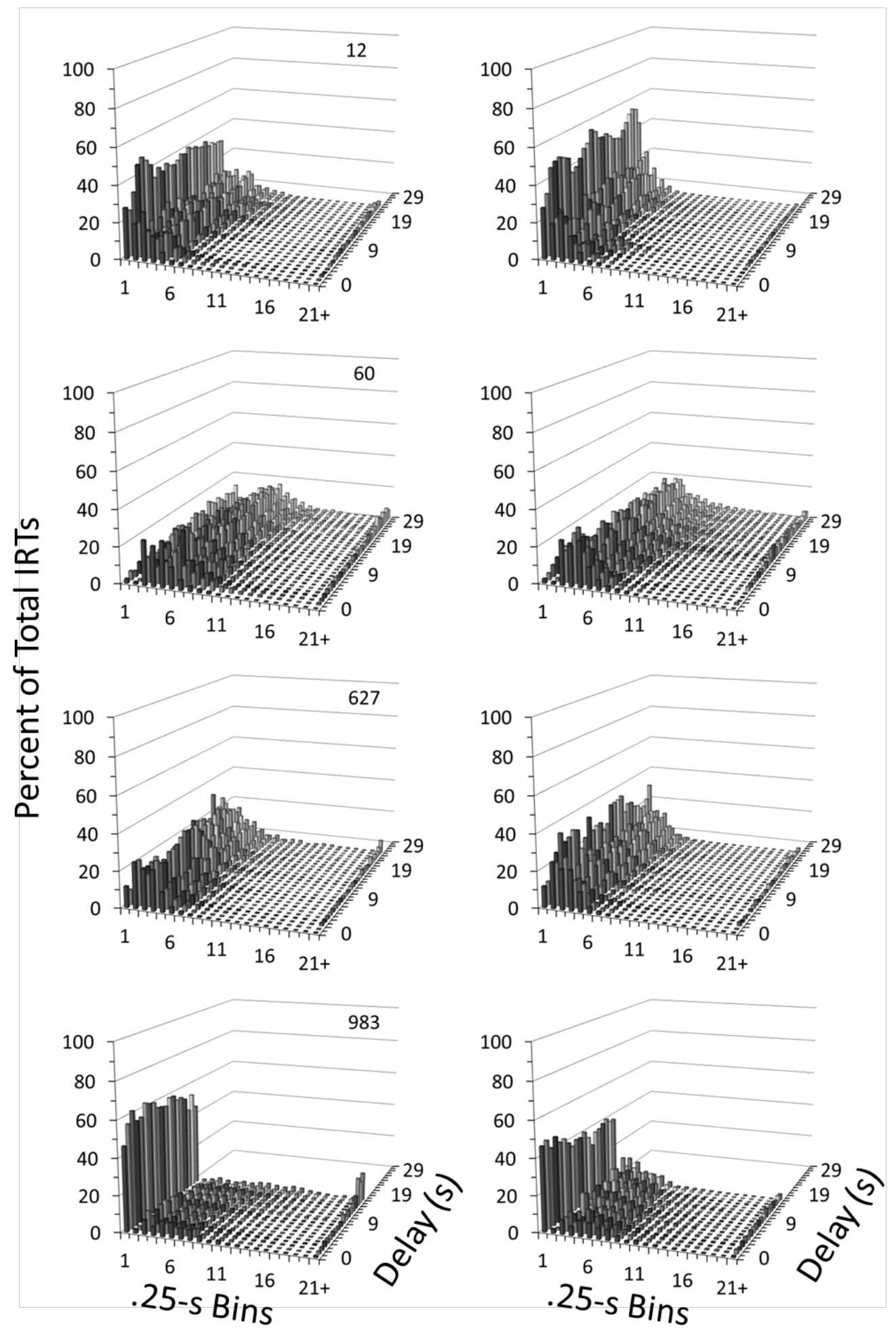

Figure 7. IRT distributions in the fixed delay component (left) and its YI control (right) of the Mixed-Signaled condition arranged as a function of the average programmed delay. 

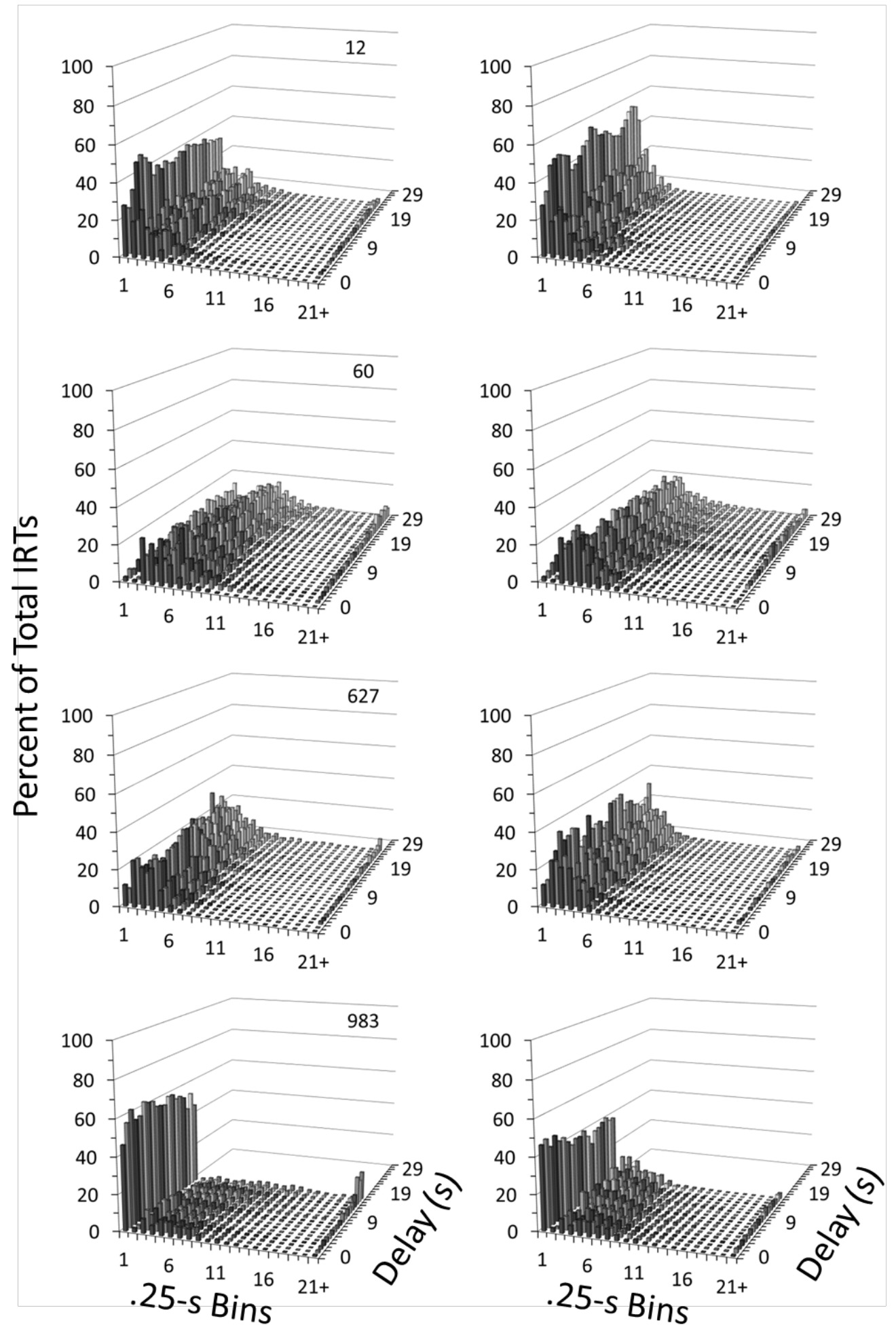

Figure 8. IRT distributions in the mixed delay component (left) and its YI control (right) of the Mixed-Signaled condition arranged as a function of the average programmed delay. 


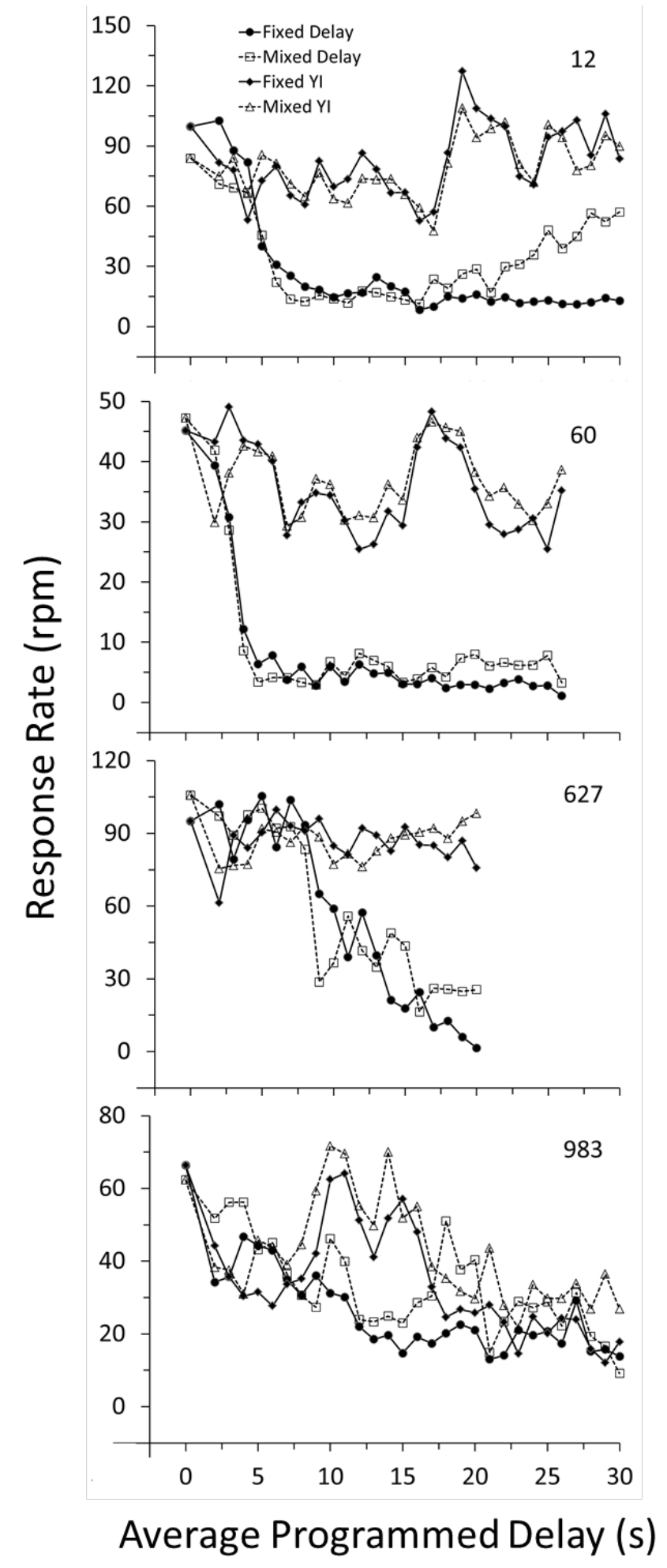

Figure 9. Absolute response rates in the Mixed-Constant condition measured as responses per minute (rpm). The last session of baseline is listed at $0 \mathrm{~s}$. 


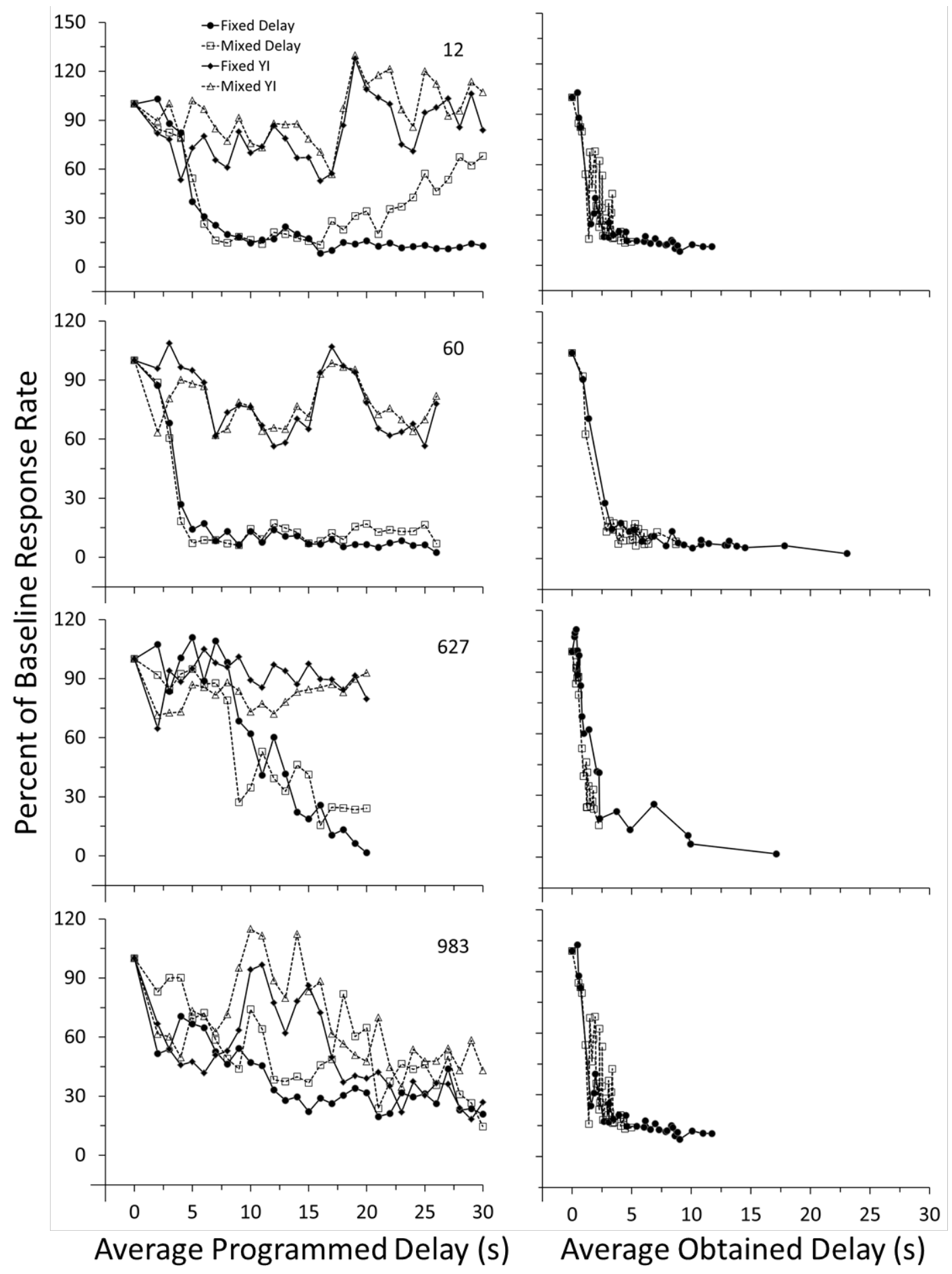

Figure 10. Response rates in the Mixed-Constant condition, measured as a percentage of responding in the last baseline session as a function of the average programmed (left) and obtained delay (right). 


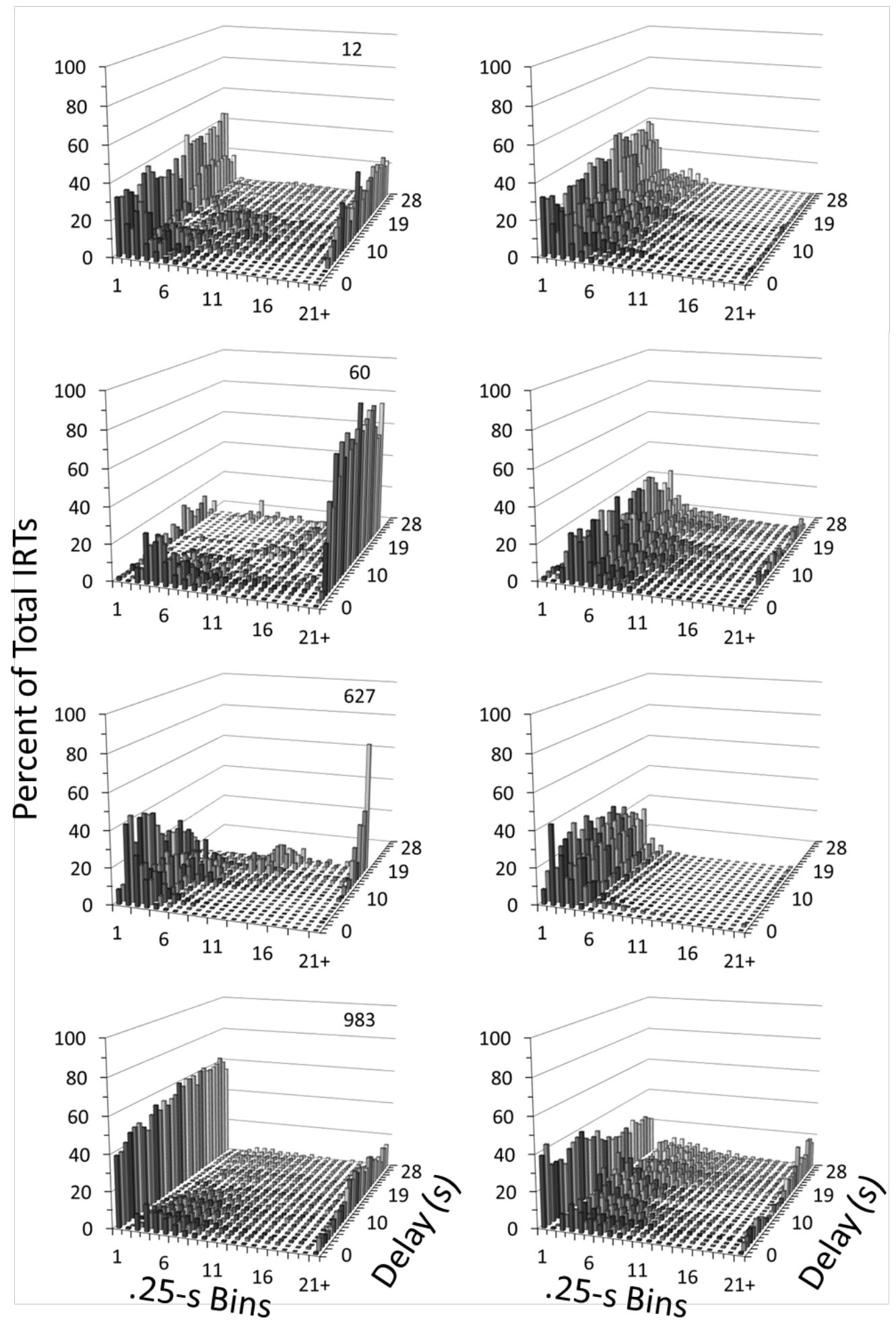

Figure 11. IRT distributions in the fixed delay component (left) and its YI control (right) of the Mixed-Constant condition arranged as a function of the average programmed delay. 


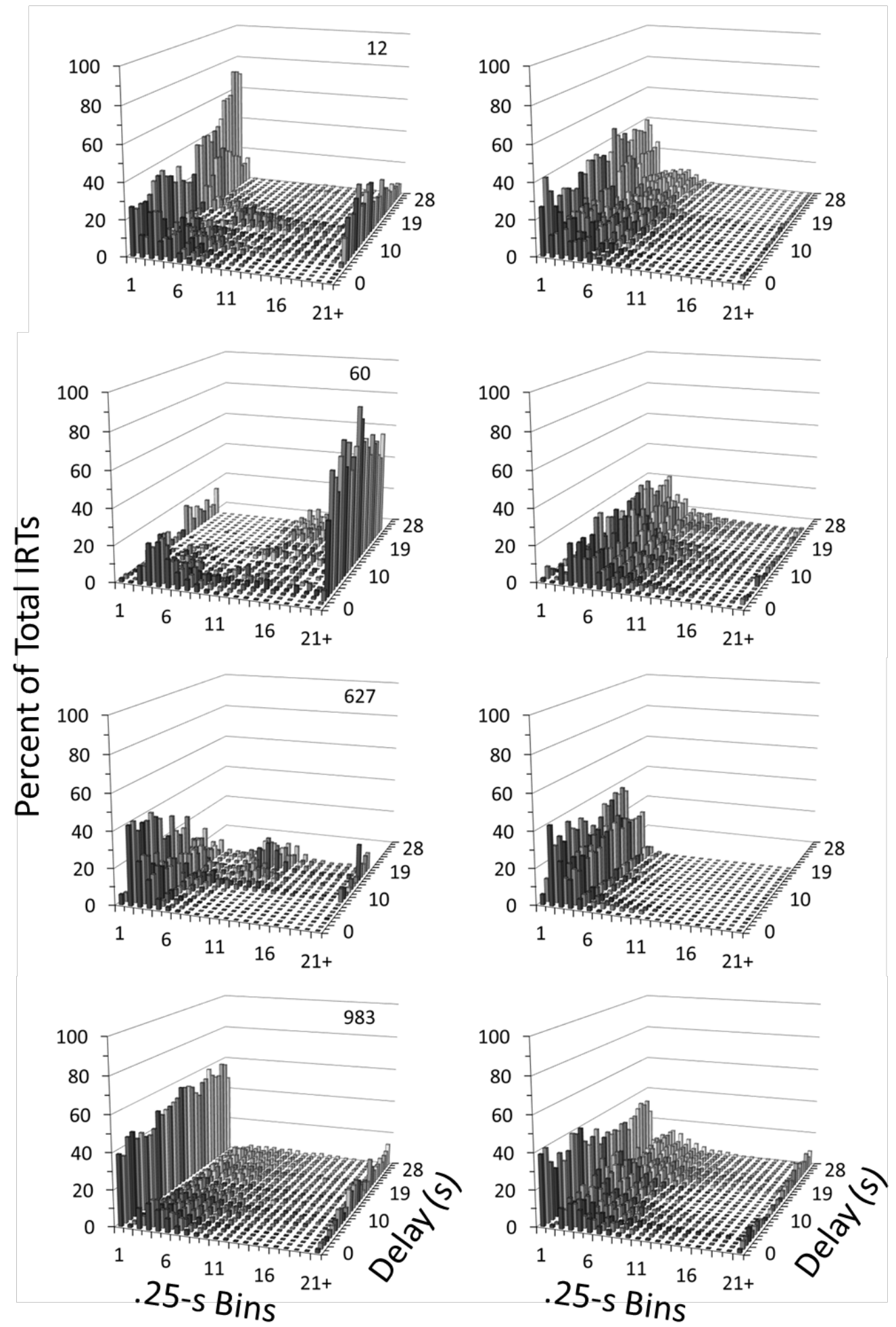

Figure 12. IRT distributions in the mixed delay component (left) and its YI control (right) of the Mixed-Constant condition arranged as a function of the average programmed delay. 


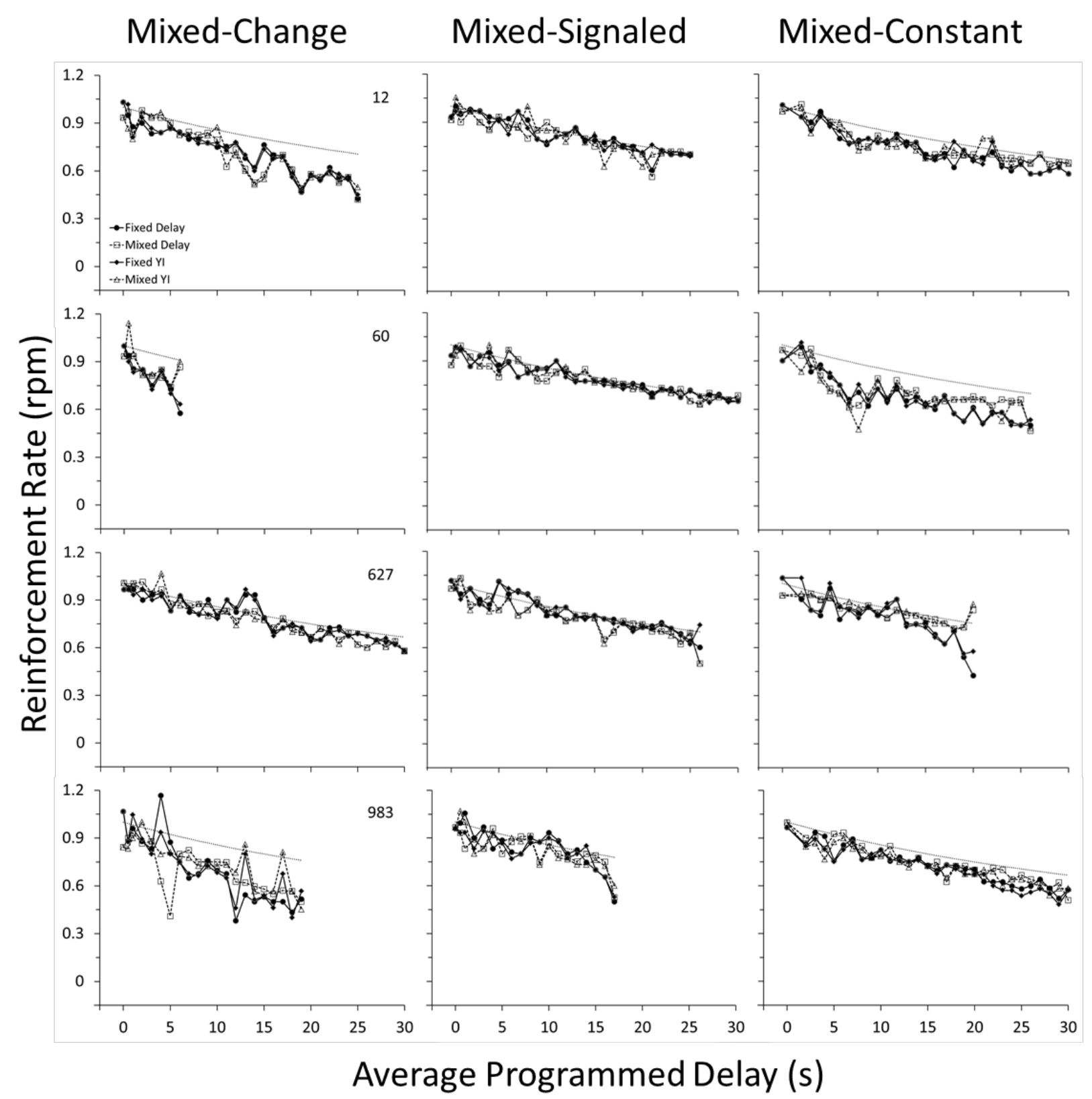

Figure 13. Obtained reinforcement rates measured as reinforcers delivered per minute (rpm) in each component of each condition for all pigeons. The dotted line depicts the programmed average reinforcement rate. 


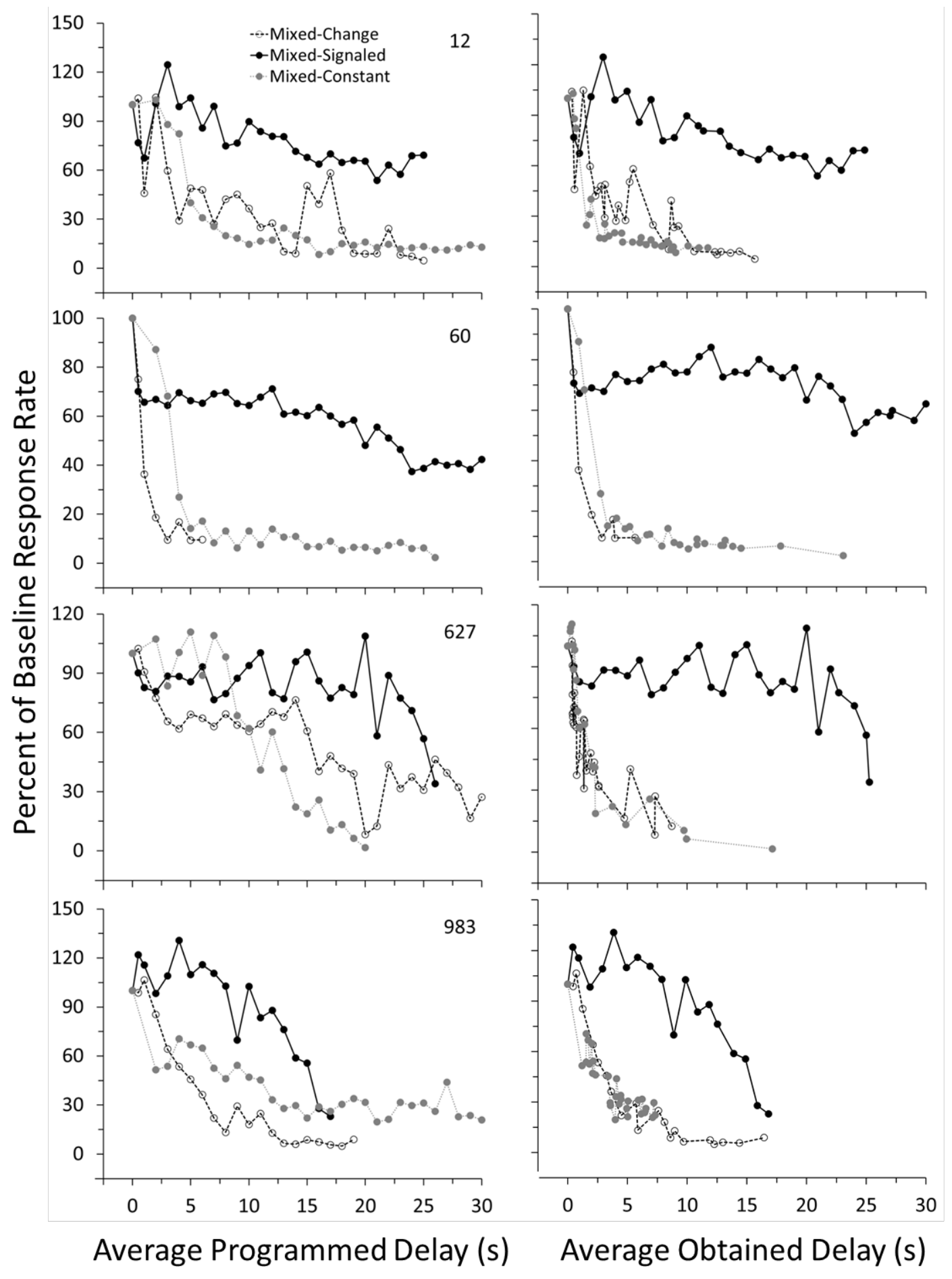

Figure 14. Response rates measured as a percentage of responding in the last baseline session in the fixed component of all conditions for all pigeons presented as a function of the average programmed (left) or average obtained delay (right). 


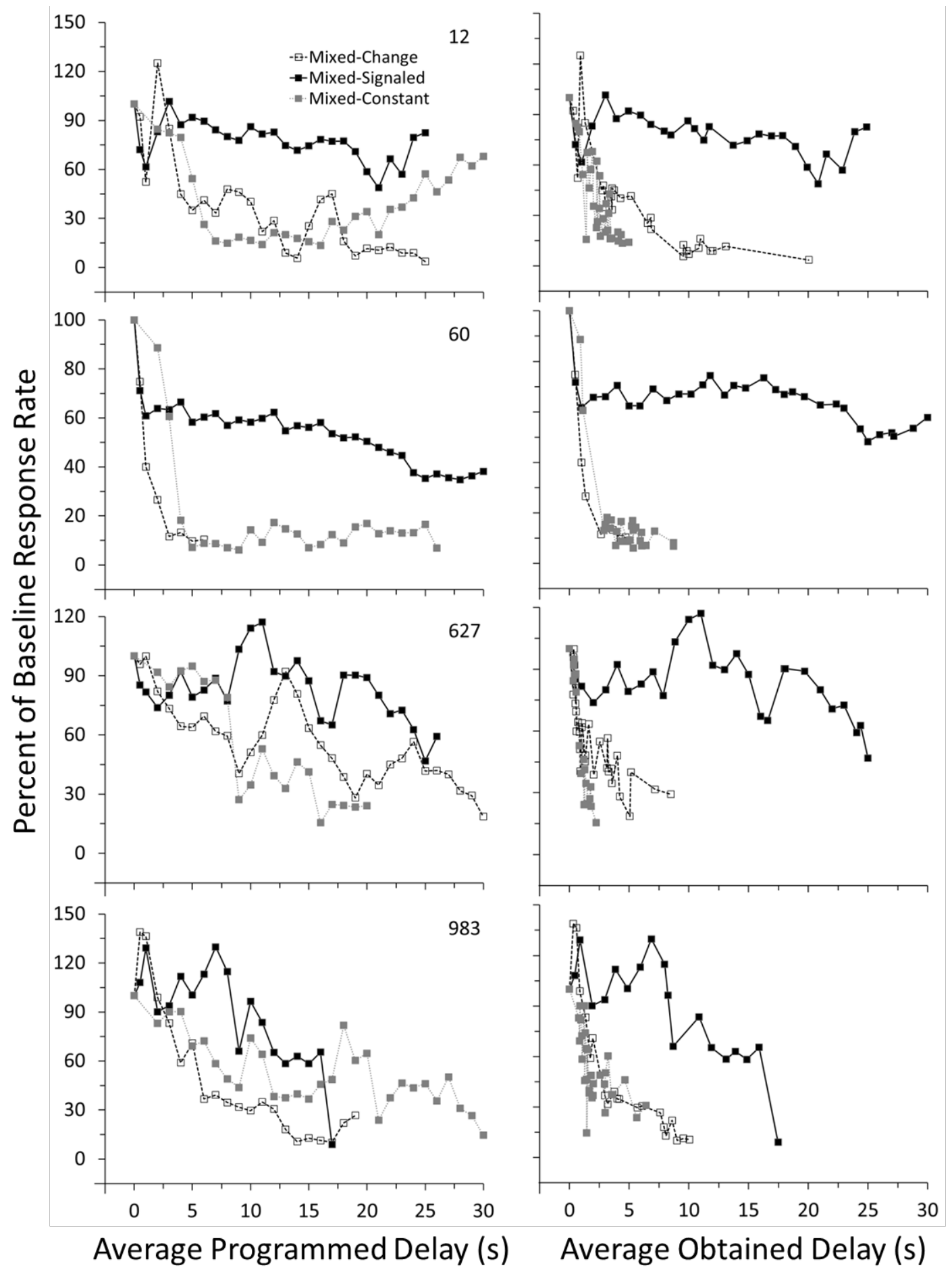

Figure 15. Response rates measured as a percentage of responding in the last baseline session in the mixed component of all conditions for all pigeons presented as a function of the average programmed (left) and average obtained delay (right). 


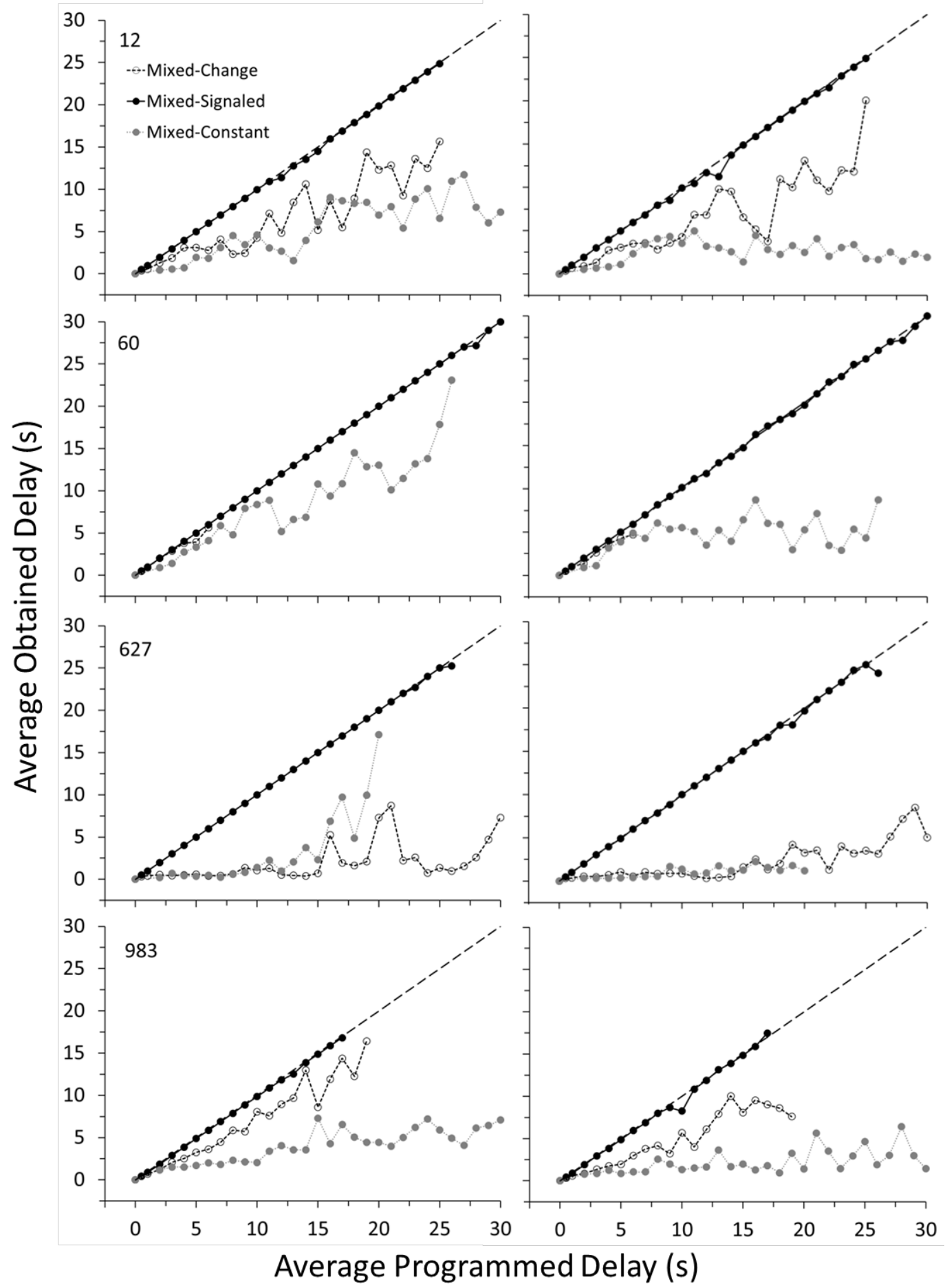

Figure 16. Average obtained delays across sessions as a function of average programmed delay for all pigeons in all conditions for the fixed (left) and mixed components (right). The dotted line depicts perfect correspondence between the obtained and programmed delays. 


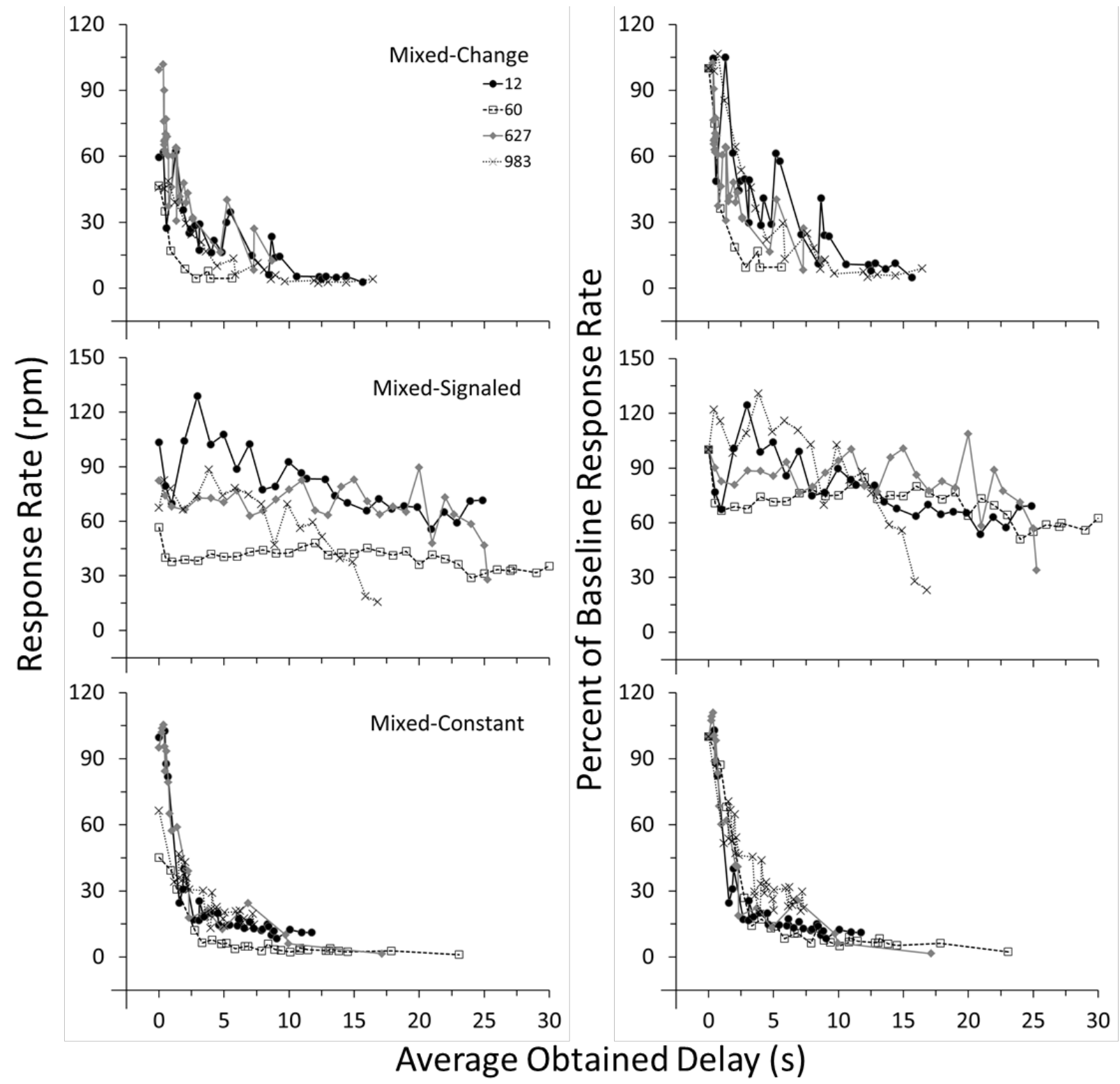

Figure 17. Absolute response rates measured as responses per minute (rpm) as a function of the average obtained delay in the fixed component of each condition for all pigeons (left), and those same data measured as a percentage of responding of the last baseline session (right). 


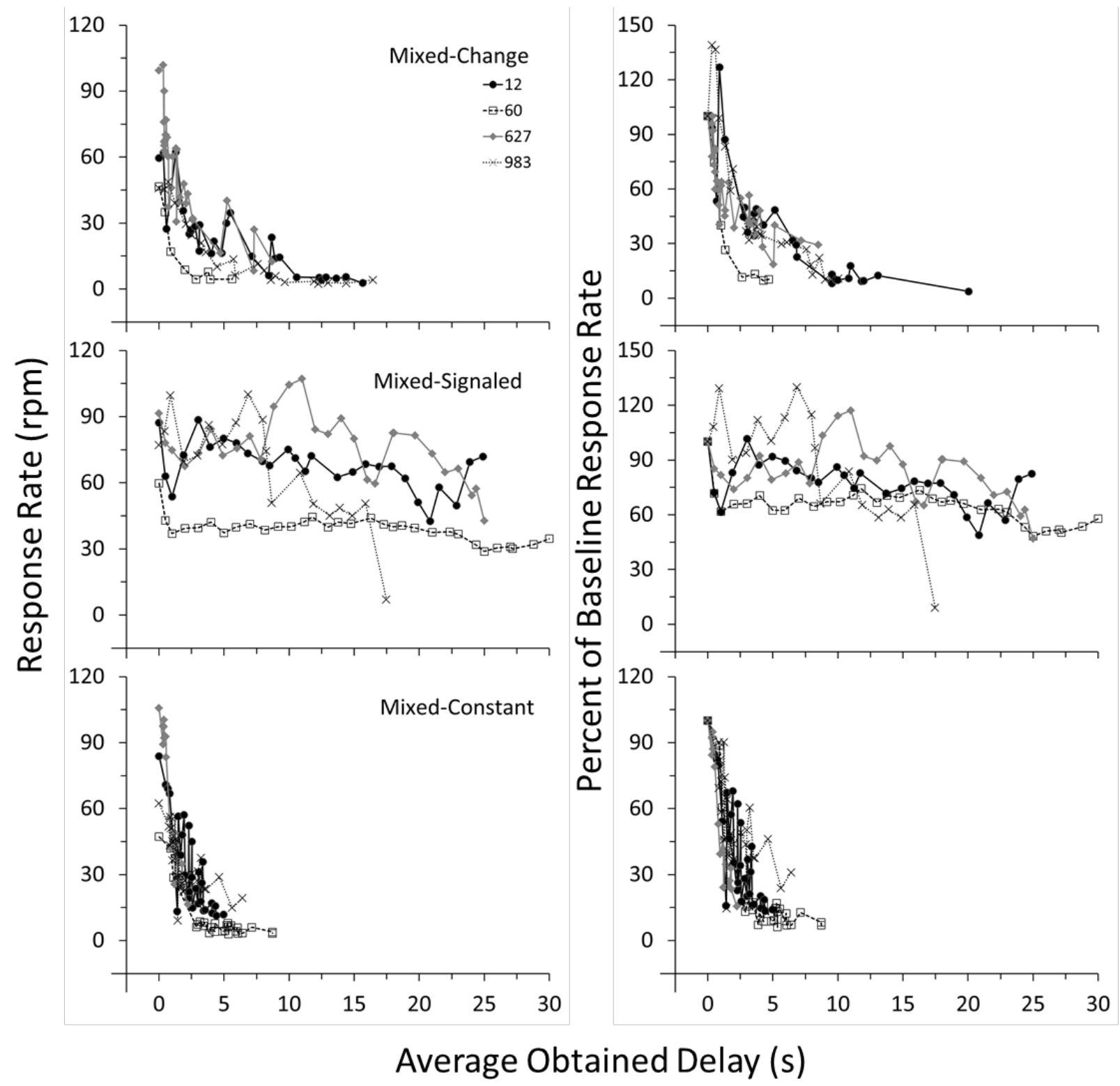

Figure 18. Absolute response rates measured as responses per minute (rpm) as a function of the average obtained delay in the mixed component of each condition for all pigeons (left), and those same data measured as a percentage of responding of the last baseline session (right). 